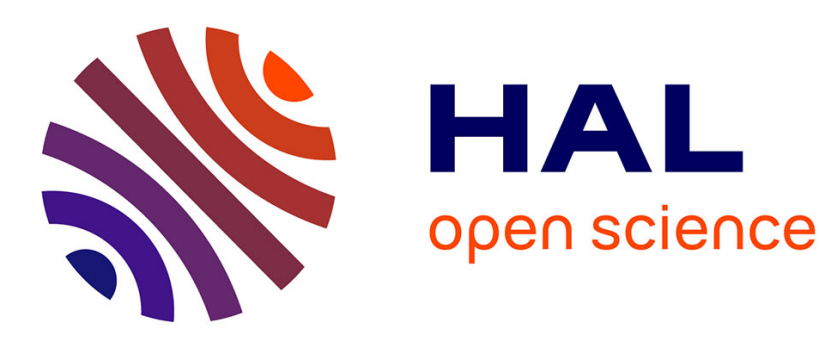

\title{
Brønsted Acid as Efficient Catalyst for Synthesis of Biologically Active Natural Products
}

\author{
Guillaume Levitre, Geraldine Masson
}

\section{To cite this version:}

Guillaume Levitre, Geraldine Masson. Brønsted Acid as Efficient Catalyst for Synthesis of Biologically Active Natural Products. István T Horváth; Max Malacria. Advanced Green Chemistry. Part 2: From Catalysis to Chemistry Frontiers, 6, World Scientific, pp.123-165, 2019, Series on Chemistry, Energy and the Environment, 978-981-121-057-0. 10.1142/9789811210587_0004 . hal-03024461

\section{HAL Id: hal-03024461 \\ https://hal.science/hal-03024461}

Submitted on 25 Nov 2020

HAL is a multi-disciplinary open access archive for the deposit and dissemination of scientific research documents, whether they are published or not. The documents may come from teaching and research institutions in France or abroad, or from public or private research centers.
L'archive ouverte pluridisciplinaire HAL, est destinée au dépôt et à la diffusion de documents scientifiques de niveau recherche, publiés ou non, émanant des établissements d'enseignement et de recherche français ou étrangers, des laboratoires publics ou privés. 


\title{
Brønsted acid as efficient catalyst for synthesis of biologically active natural products
}

\author{
Guillaume Levitre, Géraldine Masson* \\ Institut de Chimie des Substances Naturelles, CNRS UPR 2301, Université Paris-Sud, Université Paris-Saclay, 1, av. \\ de la Terrasse, 91198 Gif-sur-Yvette Cedex, France \\ Geraldine.masson@cnrs.fr
}

\section{Contents}

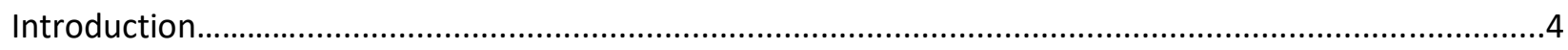

1- Enantioselective Organocatalytic Michael Additions ................................................................................

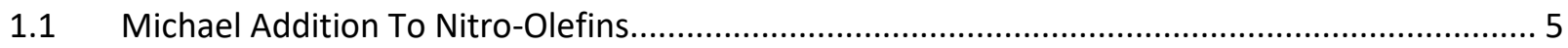

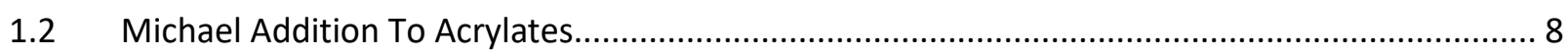

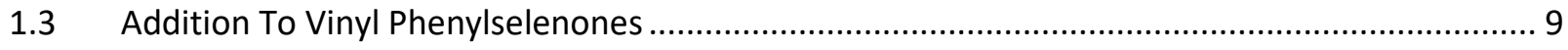

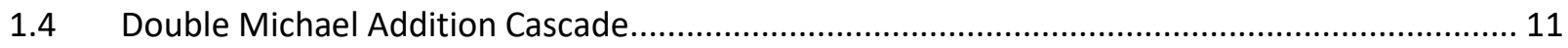

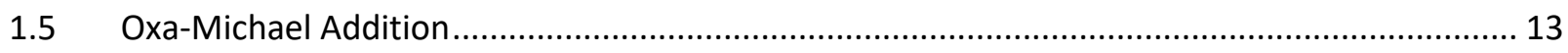

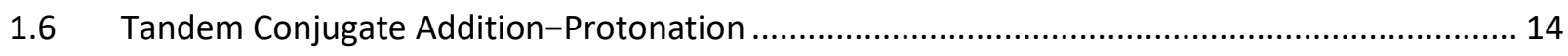

$1.7 \quad$ Michael Addition Aromatization Cascade ........................................................................... 16

2- C-C Bond Formation By Enantioselective Nucleophilic Additions Onto Activated Imines....................16

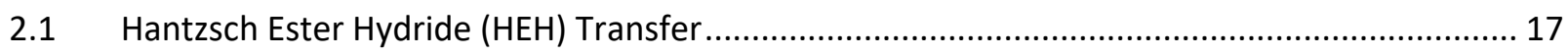

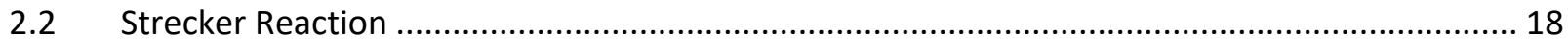

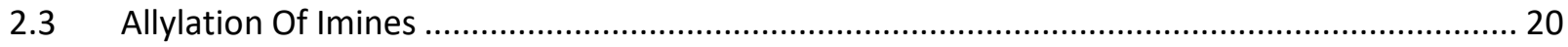

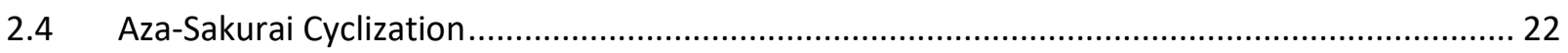

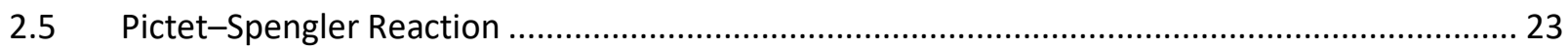

3- C-C Bond Fformation By Enantioselective Nucleophilic Additions Onto Carbonyle.............................26

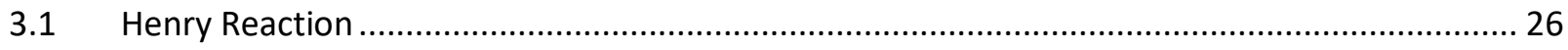

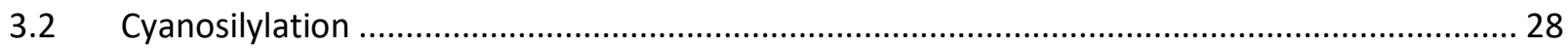

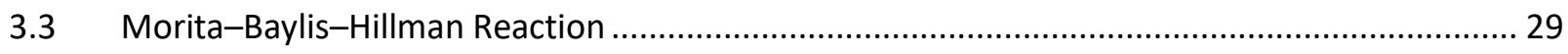

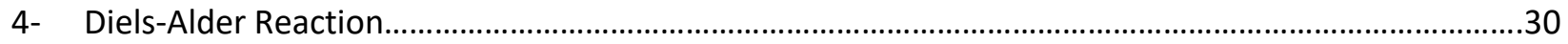

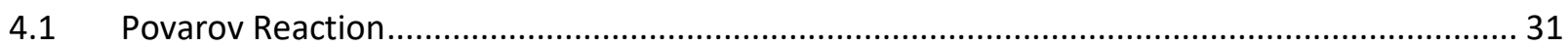

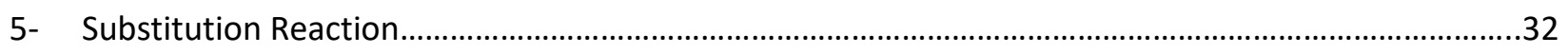

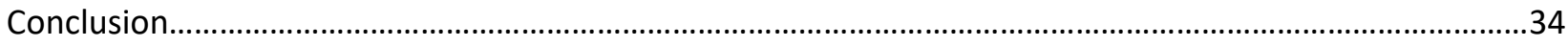




\section{List of abbreviations used}

\begin{tabular}{|c|c|c|}
\hline$\AA$ & $:$ & Angström \\
\hline Ac & : & Acetyl \\
\hline APTS & $:$ & para-toluenesulfonic acid \\
\hline Ar & : & Aryl \\
\hline BINOL & $:$ & 1,1'-binaphtalene-2,2'-diol \\
\hline Bn & $:$ & Benzyl \\
\hline Boc & $:$ & tert-butyloxycarbonyl \\
\hline bpy & $:$ & Bipyridine \\
\hline $\mathrm{Bu}$ & $:$ & Butyl \\
\hline${ }^{\circ} \mathrm{C}$ & : & Celsius Degree \\
\hline d & : & Days \\
\hline DAR & : & Diels-Alder Reaction \\
\hline$d r$ & : & Diastereomieric ration \\
\hline ee & : & Enantiomeric excess \\
\hline eq & : & Equivalent \\
\hline Et & : & Ethyl \\
\hline EWG & : & Electron Withdrawing Group \\
\hline Fmoc & : & Fluoromethoxycarbonyl \\
\hline h & : & Hour \\
\hline HEH & $:$ & Hantzsch Ester Hydride \\
\hline HFIP & : & 1,1,1,3,3,3-hexafluoroisopropanol \\
\hline HFIPA & : & 1,1,1,3,3,3-hexafluoroisopropyl acrylate \\
\hline$i \mathrm{Bu}$ & $:$ & iso-Butyl \\
\hline B-ICD & : & 6-isocupreidine \\
\hline iPr & : & iso-Propyl \\
\hline
\end{tabular}




\begin{tabular}{|c|c|c|}
\hline $\mathrm{MBH}$ & : & Morita-Baylis-Hilman \\
\hline Me & : & Methyl \\
\hline mol\% & : & Mole per cent \\
\hline MOM & : & Methoxymethyl \\
\hline Ms & : & Mesyl \\
\hline MS & : & Molecular Sieve \\
\hline MTBE & : & Methyl tert-butyl ether \\
\hline NBSA & : & ortho-nitrobenzenesulfonic acid \\
\hline Nu & : & Nucleophile \\
\hline $\mathbf{P h}$ & : & Phenyl \\
\hline Pin & : & Pinacol \\
\hline PMB & : & para-methoxybenzyle \\
\hline Red-Al & : & Sodium bis(2-methoxyethoxy)aluminium hydride \\
\hline rt & : & Room temperature \\
\hline TBS & : & tert-butylsilyl \\
\hline$t \mathrm{Bu}$ & : & tert-butyl \\
\hline Tf & : & Trifluoromethanesulfonyl \\
\hline TFA & : & Trifluoroacetic acid \\
\hline TFAA & : & Trifluoroacetic anhydride \\
\hline THF & : & Tetrahydrofurane \\
\hline TMG & : & 1,1,3,3-tatramethylguanidine \\
\hline TMS & : & Trimethylsilyl \\
\hline
\end{tabular}




\section{Introduction}

Biological properties of many drugs can be explained by the affinity of these substances for a specific macromolecular biological target such as a protein or a nucleic acid. The binding sites of such biological targets mostly form chiral environments and the configuration of a corresponding chiral ligand constitutes a crucial recognition parameter between the two partners. Consequently, such stereochimical considerations can strongly modulate the biological activity of a drug by eroding the dose-response relationship, cancelling affinity of the ligand for its target or causing antagonist effects. ${ }^{[1]}$ For those reasons, considering achiral compounds as drug candidates lowers chances of working with an optimal structure from the biological activity standpoint. Also, several examples have demonstrated the risk of using a racemic mixture as therapeutic agent. Such approaches can also be a costly and wasteful enterprise if an a posteriori resolution process has to discard half of the final target molecule. ${ }^{[2]}$ The development of synthetic operations which directly produce the highest proportion of a desired enantiomer has become a major contribution of organic chemistry to the pharmaceutical field. To reach this goal, enantioselective catalysis proved to be one of the most efficient and atom-economical approach and was extensively exploited to perform asymmetric transformations. ${ }^{[3]}$ Alternatively to organometallic catalysis, the development of organocatalysis has exploded during the last decade and naturally impacted the field of total synthesis. ${ }^{[4]}$ Interestingly, chiral organocatalysts offers various modes of activation have been involved in the preparation of numerous bioactive compounds. Recently, non-covalent organocatalysis for electrophilic activation has known a tremendous interest due to its efficiency in the asymmetric formation of $\mathrm{C}-\mathrm{C}$ and $\mathrm{C}$-heteroatom bonds.

This approach typically relies on Brønsted acid catalysts that increase the reactivity of electrophilic species by lowering their electronic density. ${ }^{[5]}$ Many privileged hydrogen bond donor scaffolds capable of forming single or double hydrogen bonds with electrophilic substrates have been developed as catalysts over past years. ${ }^{[6]}$ The use of such transformations as key steps in the synthesis of bioactive compounds is highlighted in the present report. ${ }^{[7,8]}$ However, asymmetric syntheses of natural and pharmaceutical products mediated by covalent organic catalysts $^{[3,4]}$ and phosphoric acid ${ }^{[9]}$ have been reviewed recently and are not covered in this chapter. Here, we will attempt to provide an overview of enantioselective total or formal syntheses relying on hydrogen bond organocatalysis. Notably, a focus will be put onto activation by catalyst such as bifunctional thioureas, Cinchona alkaloids, bis-imides, and BINOL derivatives 
that offer an exceptional entry to the pharmaceutically valuable compounds. In order to demonstrate the versatility of such processes and the diversity of the accessible motifs, this chapter will be organized according to target scaffolds and reaction types.

\section{1- Enantioselective Organocatalytic Michael Additions ${ }^{[10]}$}

The catalytic asymmetric conjugate addition of carbon nucleophiles to electron-deficient olefins is highly attractive transformation to design key steps during the retrosynthetic planning in total synthesis. In the area of bifunctional organocatalysis, a large number of asymmetric conjugate addition reactions have been developed to date. By acting all at once as Brønsted acids and Brønsted bases they have already demonstrated their unique efficiency in a broad range of enantioselective conjugate additions (Figure 1).

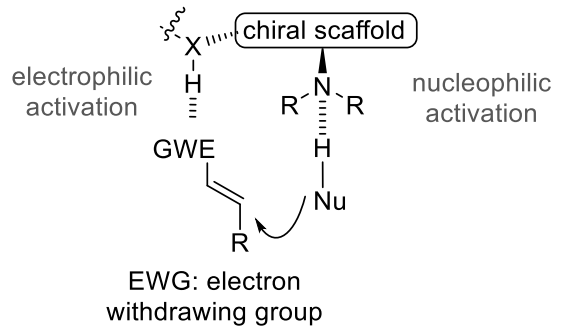

Figure 1. General scheme for the bifunctional activation by chiral bifunctional catalysts in enantioselective Michael additions.

\subsection{Michael Addition To Nitro-Olefins ${ }^{[11]}$}

Nitro-olefins are valuable building blocks in total synthesis as Michael acceptors in $\mathrm{C}-\mathrm{C}$ bond formation. Additionally, the nitro functionality is easily reduced to amine and can establish hydrogen bonding with appropriate Brønsted acid catalysts with a view to performing enantioselective transformations. In this framework, bifunctional chiral organocatalysts incorporating a thiourea and a tertiary amine moiety, proved to be particularly efficient (Figure 2). ${ }^{[12]}$ Indeed, combined activation of the electrophilic and nucleophilic partners results in high degrees of enantio- and diastereoselectivities. 


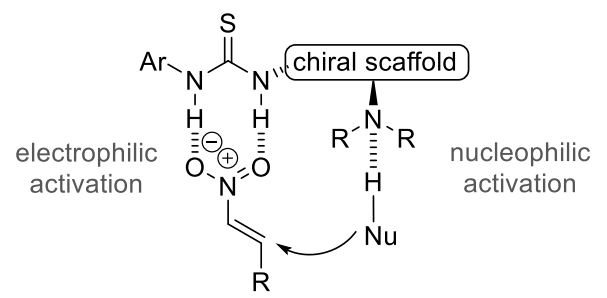

Figure 2. General scheme for the activation of nitro-olefins by chiral bifunctional thiourea-based catalysts.

The enantioselective addition of oxindoles $\mathbf{2}$ to nitro-olefins $\mathbf{1}$ is a powerful application of organocatalysis by Brønsted acids and appears as an efficient method for the direct construction of all-carbon quaternary stereogenic centers. Barbas III and co-workers developed a thioureacatalyzed process permitting the formation of oxindoles $\mathbf{4}$ in a single step triggered by catalyst 3 (Scheme 1). The two adjacent stereogenic centers, including the quaternary C3 position, were generated in a highly enantio- and diastereoselective fashion. The method offers a privileged access to the hexahydropyrroloindole core encountered in numerous alkaloid derivatives. Hence, this reaction was used as a key step to achieve the formal synthesis of the calabar alkaloid (+)-physostigmine, an Alzheimer's disease therapeutic agent. ${ }^{[13]}$ Based on the same method, catalyst 3 was employed to prepare compound 4 a, isolated in $65 \%$ yield and with $96 \%$ ee after a single recrystallisation step. Further post-transformations, including the reduction of the nitro substituent to afford amine 6, ended with the isolation of tricylic (+)-esermethole 7. As demonstrated by Overman ${ }^{[14]}$ and Brossi, ${ }^{[15]}$ this molecule is an advanced intermediate in the synthesis of of (+)-physostigmine 8 . Finally, the strategy developed by Barbas III constitutes an attractive alternative to the previous syntheses of this target molecule. ${ }^{[16,17,18]}$ 

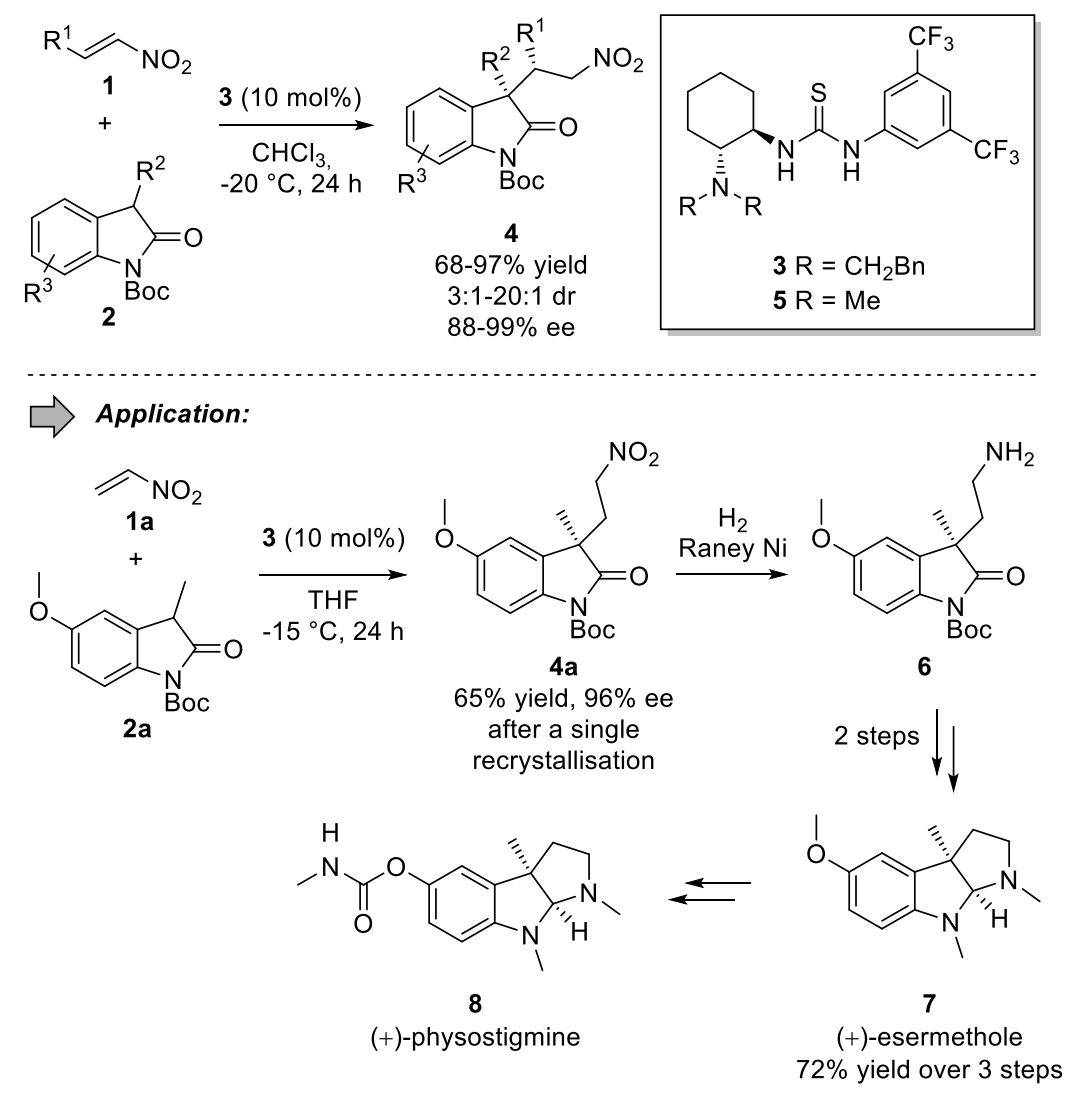

Scheme 1. Synthesis of (+)-physostigmine

In 2015, Nagasawa and co-workers ${ }^{[19]}$ reported an enantioselective Michael addition of a phenol 9 with a nitro-olefin $\mathbf{1 0}$ in the presence of guanidine/bisthiourea organocatalyst $\mathbf{1 1}$ (Scheme 2). An inseparable mixture of diastereomers $\mathbf{1 2}$ was isolated at this step. After triflation of the phenol unit, the Michael compound 13 was isolated in good yield with 93\% ee. The authors proposed a possible transition state to explain the high enantioselectivity, in which the guanidine moiety of catalyst activates the phenol as a nucleophile, and at the same time the thiourea moiety activates the nitro-olefin. The synthetic value of this method was further demonstrated by its involvement in the total synthesis of amaryllidaceae alkaloid (+)-trans-dihydrolycoricidine $\mathbf{1 5}$. Several transformations such as olefin oxidative cleavage, intramolecular Henry reaction, CO insertion reaction and stereoselective hydroxylation were required to reach tricyclic 14 . Targeted product 15 was then reached after 3 steps. 

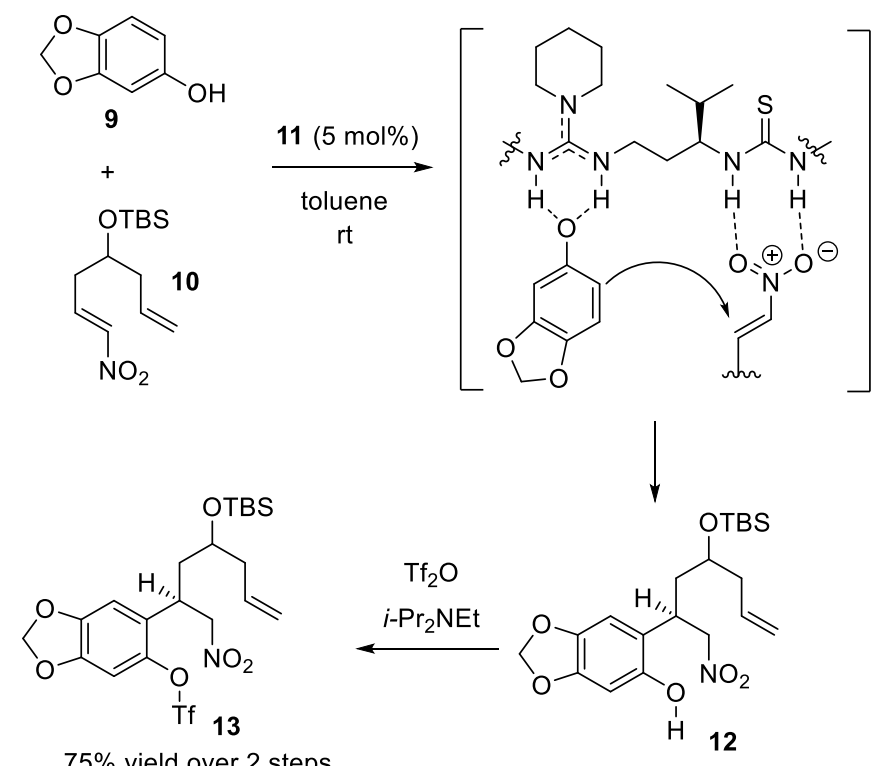

$75 \%$ yield over 2 steps

$93 \%$ ee

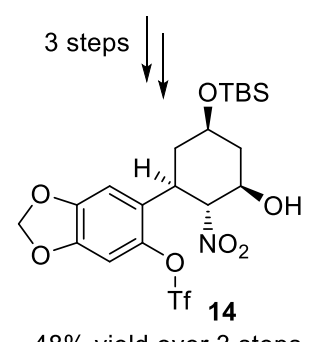

$48 \%$ yield over 3 steps separtaion of diastereomer

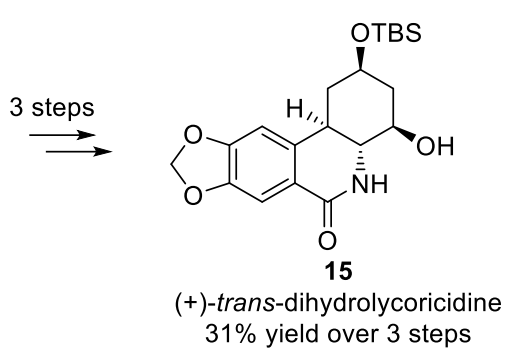

$31 \%$ yield over 3 steps<smiles>CC(C)[C@H](CCN=C(NCC[C@H](NC(=S)Nc1cc(C(F)(F)F)cc(C(F)(F)F)c1)C(C)C)N1CCCCC1)NC(=S)Nc1cc(C(F)(F)F)cc(C(F)(F)F)c1</smiles>

Scheme 2. Synthesis of (+)-trans-dihydrolycoricidine

\subsection{Michael Addition To Acrylates [20]}

In 2011, Fan and co-workers reported ${ }^{[21]}$ the total synthesis of three naturals products relying on an enantioselective Michael of $\alpha$-aryl- $\alpha$-cyanoketones 16 and 4-iodophenyl acrylate 17. Moderate level of enantioselectivity was observed using chiral bifunctional thiourea catalyst $\mathbf{1 8 ,}$ however the enantiopure compounds 19 was isolated after recrystallization (Scheme 3). Moreover, the Michael product $\mathbf{2 1}$ with the opposite configuration were prepared by using Takemoto catalyst 20. ${ }^{[22]}$ Interestingly, the reaction affords quaternary stereocenters bearing 
substituents that were exploited in the synthesis of three natural products like lycoramine $\mathbf{2 2}$, galanthamine $\mathbf{2 3}$ and lunarine $2 \mathbf{2 4}$

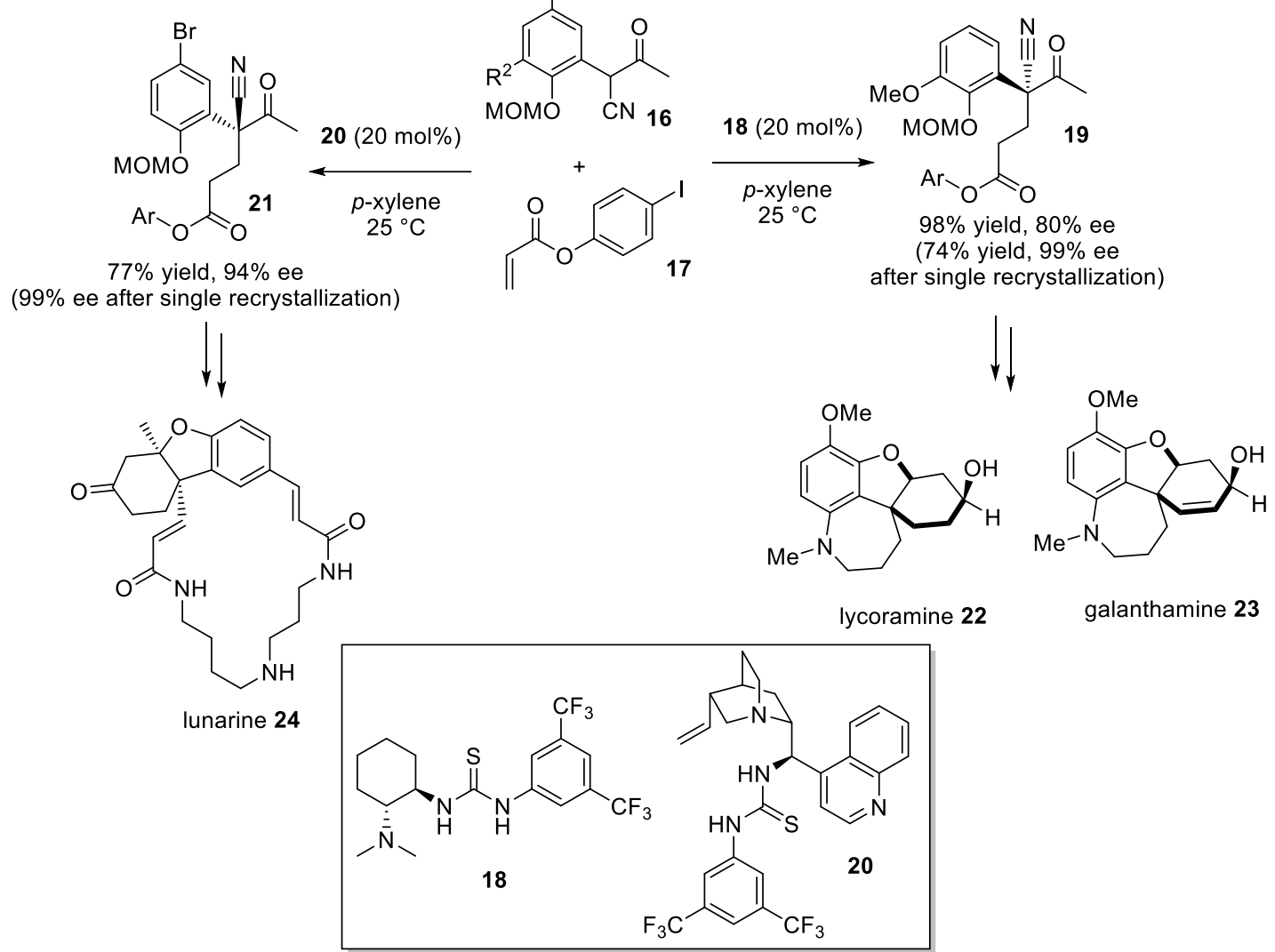

Scheme 3. Synthesis of lycoramine, galanthamine and lunarine

\subsection{Addition To Vinyl Phenylselenones}

Selenones are important motifs in organic synthesis, because the selenonyl group is a good leaving group, offering an opportunity to undergo further derivatization for the synthesis of natural product. In 2009, Marini and co-workers ${ }^{[23}$ reported the first enantioselective organocatalytic addition of $\alpha$-substituted cyanoacetates to vinyl selenones. Two years laters, Liu and coworkers ${ }^{[24]}$ developed an enantioselective Michael addition of 2-oxindoles 25 to $\alpha, 6$-unsaturated selenones 26 catalyzed by a Cinchona alkaloid-based thiourea 20 in roomtemperature ionic liquids (Scheme 4). High to excellent yields and enantioselectivities were achieved. The suggested transition state $\mathbf{2 8}$ displays a network of hydrogen bonds between the reactions partners initiated by the bifunctional catalyst. This strategy for the preparation of 
bioactive molecules was highlighted by the synthesis of (-)-physostigmine 29 . Indeed, the target was obtained in three steps from Michael adduct in a $62 \%$ overall yield.
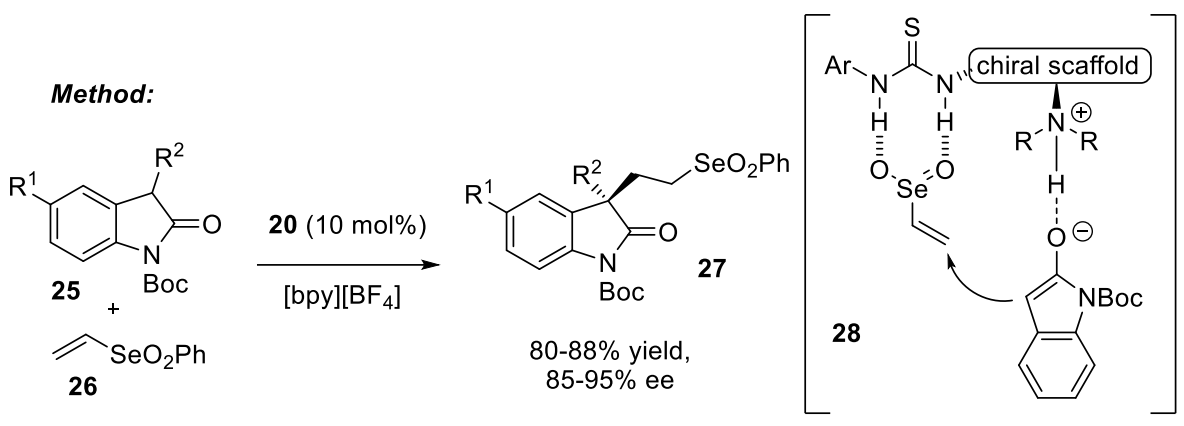

$\Rightarrow$ Application:
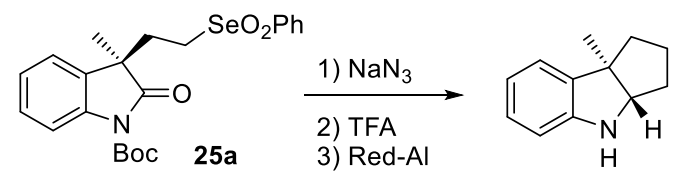

$88 \%$ yied, $95 \%$ ee

(-)-physostigmine 29

$62 \%$ yield over 3 steps

Scheme 4. Synthesis of physostigmine

Recently, the group of Zhu ${ }^{[25]}$ published a Cinchona-catalyzed method for the preparation of optically active isocyano-bonding quaternary carbon. The reported procedure involves a Michael addition of a 2-isocyanoarylacetate $\mathbf{3 0}$ to vinyl phenylselenone $\mathbf{3 1}$ (Scheme 5). The catalyst having a free hydroxy group on the C-6' position was found to be the best in terms of reactivity and enantioselectivity. Once again, the bifunctional aspect of catalyst was invoked to explain the degree of stereocontrol. This elegant strategy was highlighted by the synthesis of trigonoliimine A 34. Indeed, the target was obtained in six steps from 33 in a $22 \%$ overall yield. 


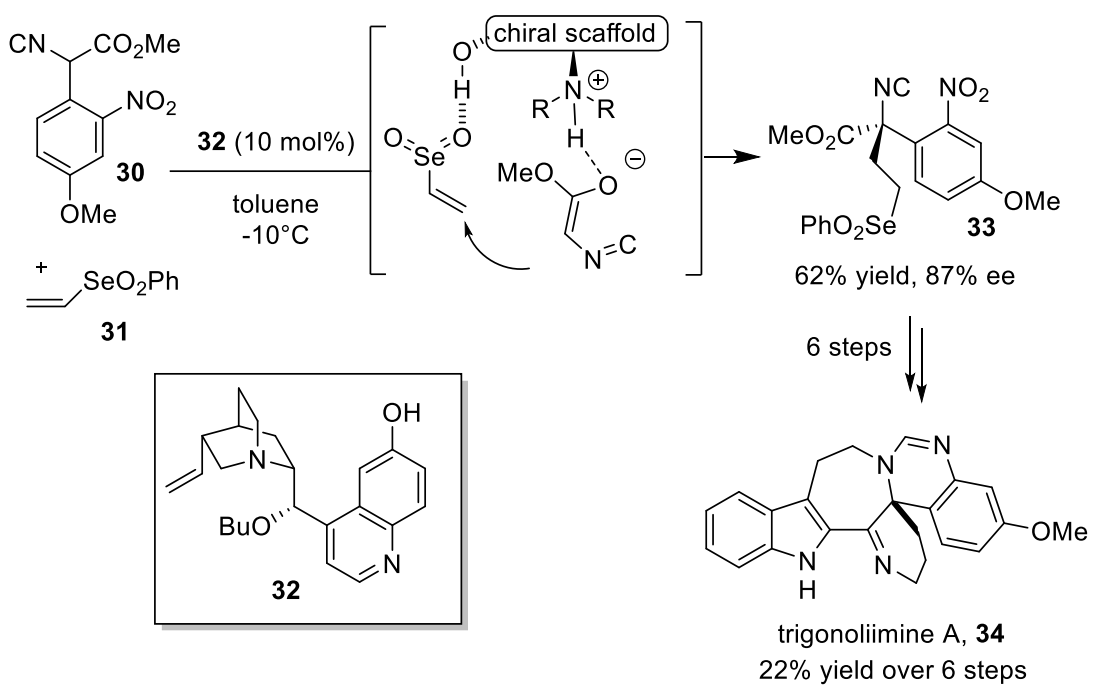

Scheme 5. Synthesis of trigonoliimine A

\subsection{Double Michael Addition Cascade}

Brønsted acids-catalyzed cascades involving nitro-alkenes have been extensively used to quickly increase molecular complexity starting from simple substrates. Notably, double Michael addition sequences $^{[26]}$ have been used to afford, after a unique step, elaborate (poly)cyclic structures displaying multiple stereogenic centers in a one-pot fashion. These transformations rely on nucleophilic partners $\mathbf{3 5}$ including a Michael acceptor (Scheme 6). Therefore, the initial Michael addition onto activated nitro-olefin $\mathbf{1}$ is followed by a second intramolecular conjugate addition. In this context, Takemoto and co-workers reported a chiral thiourea-catalyzed process involving $\gamma, \delta$-unsaturated $\mathbf{6}$-ketoesters $\mathbf{3 6}$ and nitrostyrene $\mathbf{1 b}$ as substrates (Scheme 7). ${ }^{[27]}$

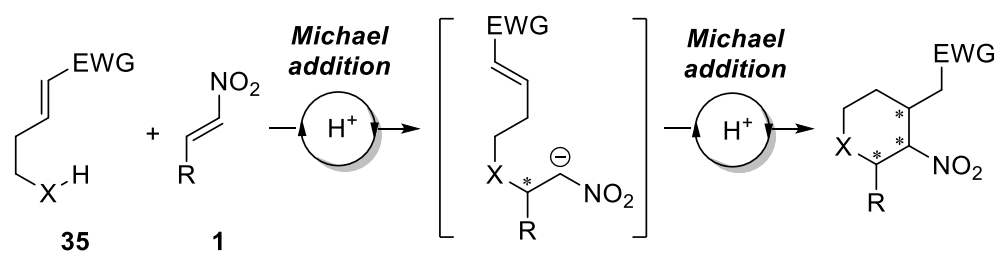

Scheme 6. General scheme for the Brønsted acid catalyzed double Michael addition of nitro-olefins

In this case, the cyclization step requires the subsequent addition of a strong base to proceed. Desired cyclic intermediates $\mathbf{3 7}$ were then obtained with good enantio- and diastereoselectivities, since the 3,4-trans-4,5-cis diastereomers were isolated up to $92 \%$ ee. This work constitutes the first description of a nitroalkenes-triggered reaction supporting the formation of three contiguous 
stereogenic centers. The resulting optically active six-membered rings can serve as chiral scaffolds in the construction of supplementary cyclic structures. Hence, one of these motifs was exploited to achieve the synthesis of (-)-epibatine, a toxic alkaloid isolated from frog skin with a capacity to bind to nicotinic and muscarinic acetylcoline receptors. Slightly modified reaction conditions were involved in the preparation of intermediate 37a. Indeed, a solution of $\mathrm{KOH}$ in $\mathrm{EtOH}$ was used to ensure that cyclization occurred without epimerization of the $\mathrm{NO}_{2}$-substituted stereocenter. Compound 37a was then isolated as a single diastereomer in $85 \%$ yield but with a moderate enantiopurity, while the latter could be increased to $99 \%$ by recrystallization of an advanced intermediate of the synthesis. Product 37a was then converted into molecule $\mathbf{3 8}$ in 5 steps and with $39 \%$ overall yield. Interestingly, the presence of the nitro group was ingeniously exploited in the last step as an amine precursor to reach the bridged core of (-)-epibatidine 39.
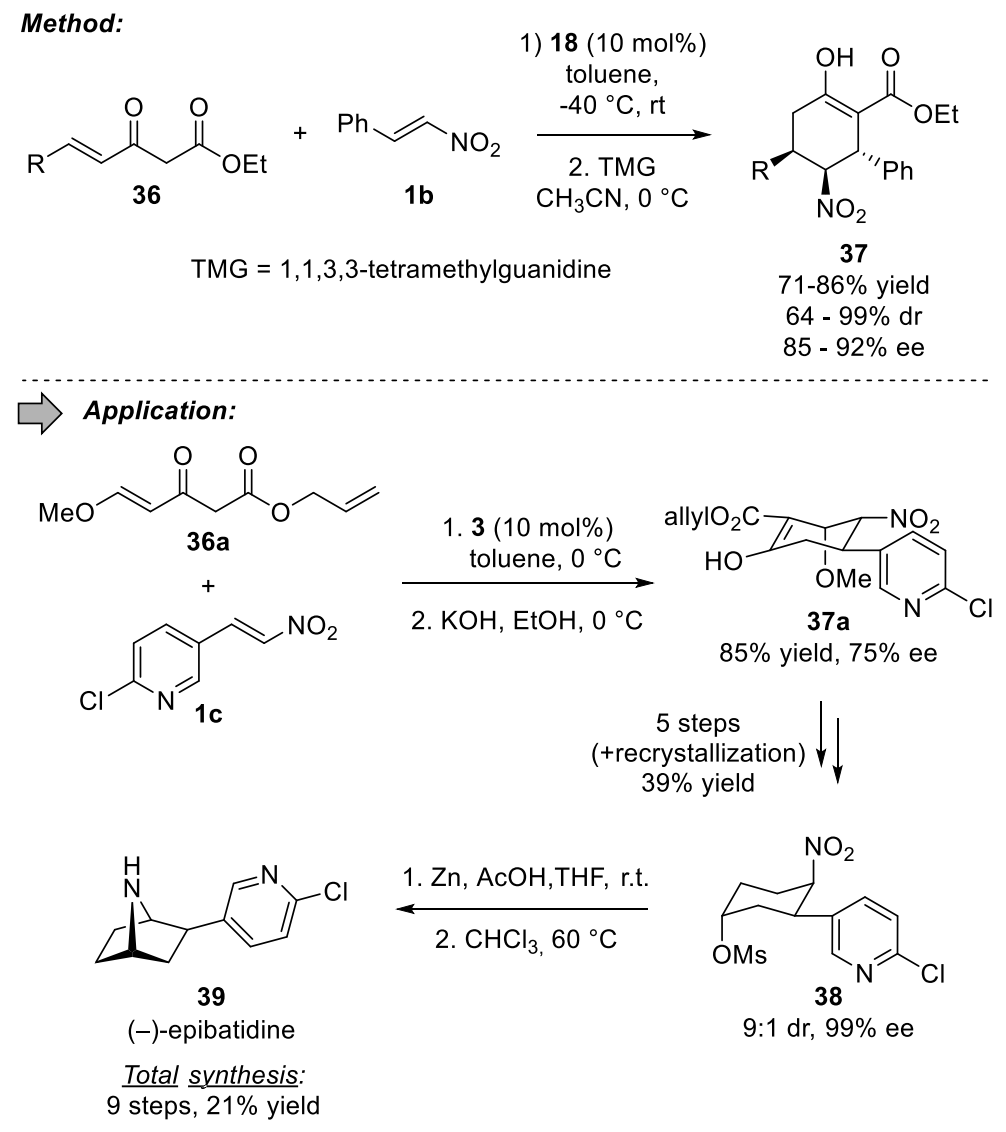

Scheme 7. Synthesis of (-)-epibatidine

As illustrated by the structures of (+)-physostigmine or (-)-epibatidine, alkaloids constitute a highly heterogeneous family of bioactive molecules. Their structural affiliation only relies on the 
presence of a basic nitrogen atom and, in most cases, a heterocyclic scaffold. However, this loose description remarkably fits with the products recovered after a synthetic sequence including an organocatalyzed double Michael addition of nitro olefins and the reduction of the nitro substituent. Thus, very different alkaloids can be prepared using similar catalysts in similar key transformations by simply varying the nature of the substrates. As a matter of fact, Xu proposed a thiourea-catalyzed double Michael addition between malonate $\mathbf{4 0}$ and nitroalkene $\mathbf{1 d}$ to install the $\mathrm{C}$ ring of tetracyclic $\alpha$-lycorane 42 (Scheme 8). ${ }^{[28]}$ In this case, no additional base was required and the desired the six-membered ring 41 was isolated as a single diastereomer (12:1 dr) in 95\% yield and $90 \%$ ee. As a masked imine, the nitro group had a central role in the subsequent formation or $D$ and $B$ rings. Impressively, this retrosynthetic analysis allowed the preparation of $\alpha$-lycorane in 9 steps and $21 \%$ overall yield.

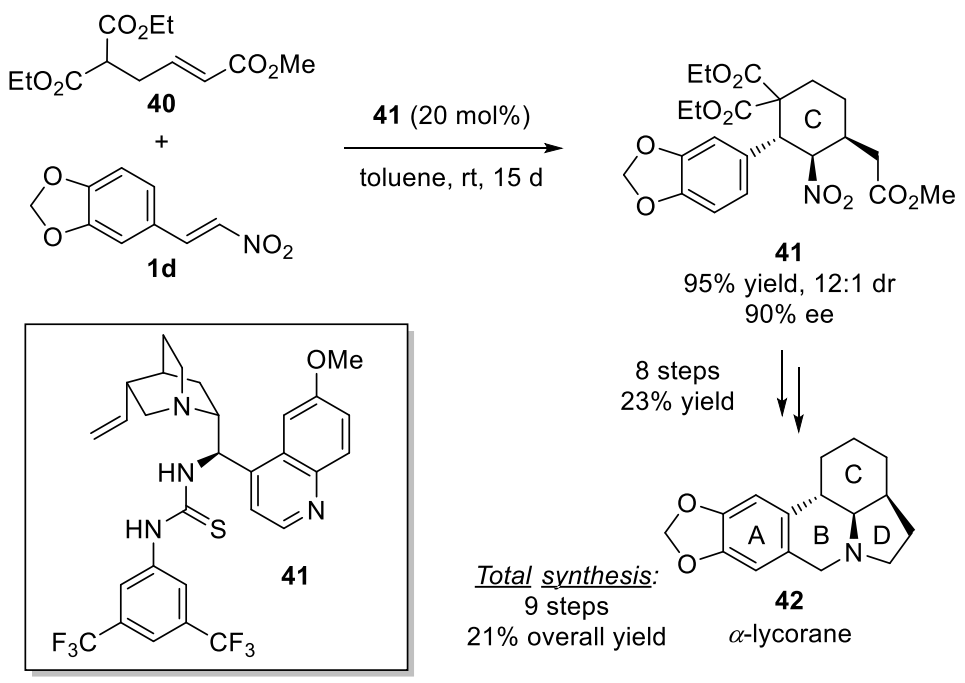

Scheme 8. Synthesis of $\alpha$-lycorane

\subsection{Oxa-Michael Addition}

Oxa-Michael additions, in which the nucleophile is an oxygen atom, are a good entry to prepare 6 -hydroxy ketones, which are found in many natural products. In 2008, the group of Falk described an enantioselective preparation of such derivate starting from $\alpha, b$-enone and using chiral bifunctional thiourea as catalyst. ${ }^{[29]}$ In the presence of phenylboronic acid, $\boldsymbol{\gamma}$-hydroxy enone 43 formed the corresponding hemi boronate $\mathbf{4 4}$ which undergo a hydroxyl transfer through the help of the chiral catalyst 41. This hydroxyl transfer was believed to proceed via the push/pull nature of the catalyst, ${ }^{[30]}$ coordinating the carbonyl of the enone (thiourea moety, pull effect) and 
exibiting its electrophily. Then, the quinuclidine moiety (tertiary amine, pull effect) coordinates the boron center, increasing the nucleophily of the hydroxyl group. Finally, oxidative cleavage of the boron-oxygen bonds liberated the diol 45a in both excellent $90 \%$ overall yield and $91 \%$ ee. Then, the primary alcohol was selectively acetylated to give the natural product $(R, 12 Z, 15 Z)-2$ hydroxy-4-oxohenicosa-12,15-dienyl acetate 46. In addition, the authors reported the synthesis of $(+)-(S)$-Streptenol $45 \mathrm{~b}$, using the same catalyst 41 . Electron rich phenyl boronic acid such as 3,4,5-trimethoxyphenyl boronic acid was required to proceed at an acceptable rate and enantioselectivity. Finally, after oxidative cleavage, the natural product $45 \mathrm{~b}$ was obtained with a good overall $75 \%$ yield and a good $88 \%$ ee.

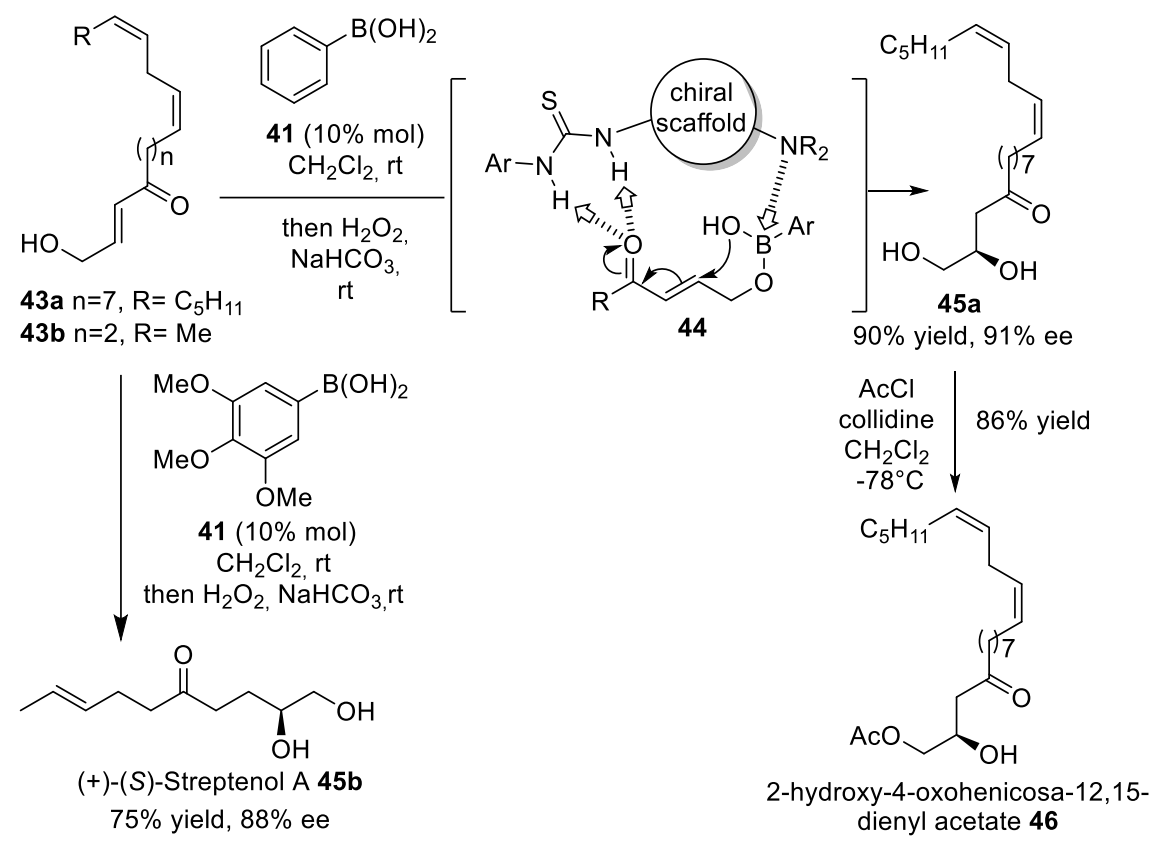

Scheme 9. Enantioselective synthesis of $b$ - and $\gamma$-hydroxy ketone by oxa-Michael addition

\subsection{Tandem Conjugate Addition-Protonation}

In 2007, Deng and co-workers developed an enantioselective entry to 1,3-disubstitued carbon framework bearing a tertiary and quaternary centers, using a cinchona based bisfunctional catalyst 49 (Scheme 10). ${ }^{[31]}$ The reaction between 2-chloroacrylonitrile 48 and $\alpha$-cyanothioester 47 proceeds in two sequential stereo-induction steps. The first step involves asymmetric conjugate addition via a well-organized transition state $\mathbf{5 0}$ between catalyst and substrates. In the second step, the nucleophilic addition of the enol on the 2-chloroacrylonitrile followed by protonation give the product $51 \mathrm{a}$ in $71 \%$ yield and $93 \%$ ee. With this key intermediate in hand, the author set out the formal synthesis of manzacidin A 55a. The nitrogen was introduced by 
nucleophilic substitution of chloride to azide. Then, the methanolysis of the less-hindered cyanide group followed by reduction lead to the diol 52a. Silylation of the diol, hydrolysis of the remaining cyanide, hydrogenation and Boc-protection gave 53a. The, the Hoffman rearrangement and deprotection of silyl group led the common intermediate 54a of synthesis manzacidin A 55a developed by Ohfune et al.

Shortly after the same author reported a method which afforded the complementary sense of diastereoselectivity in this enantioselective tandem asymmetric Michael addition-protonation process by using the cinchona catalyst bearing a thiourea moiety 41 (Scheme 10). ${ }^{[29]}$ They could prepare the Michael adduct 51b, in $98 \%$ yield and $96 \%$ ee. According to the synthetic plan described above, the formal synthesis of manzacidin C 55b was achieved.

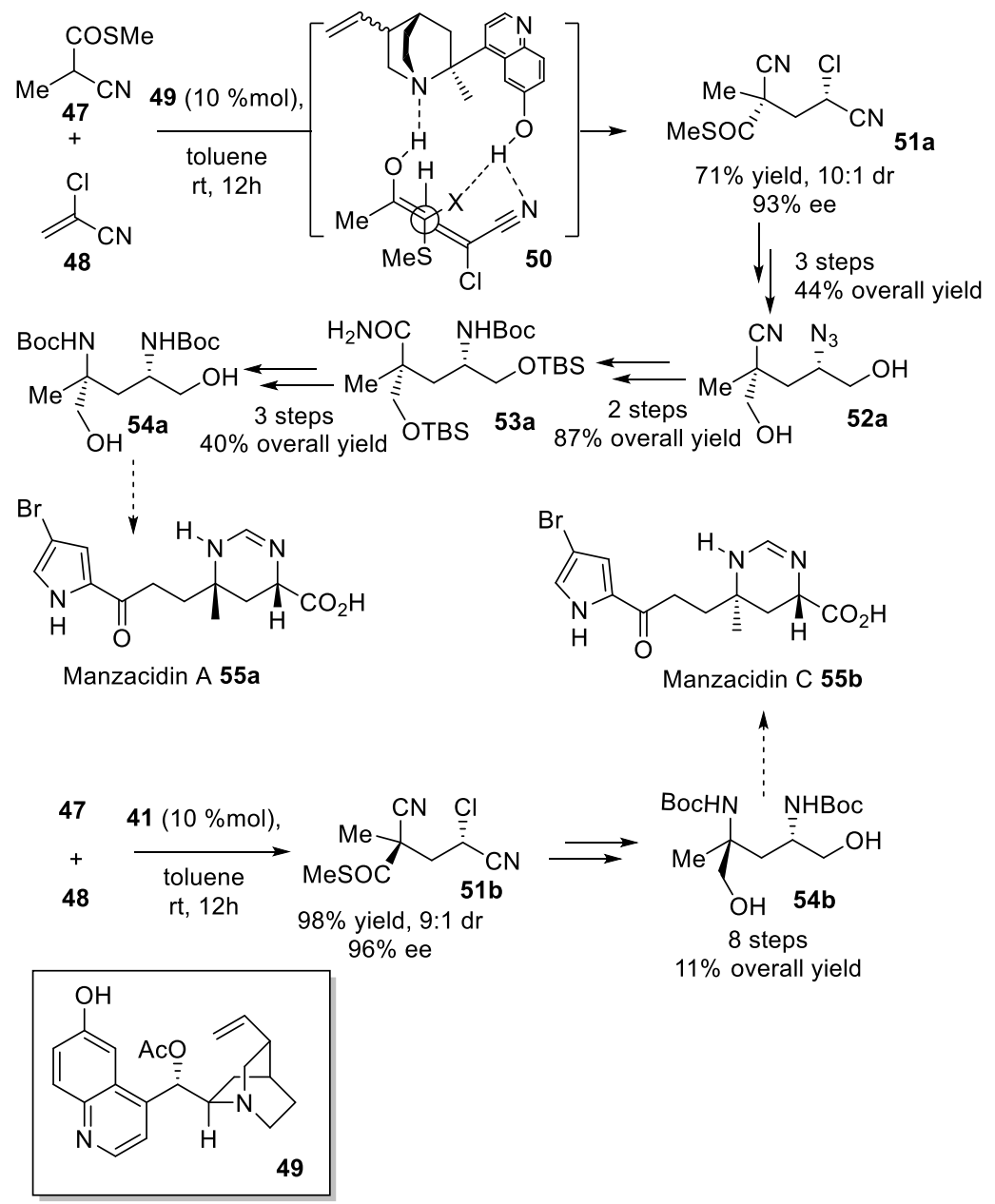

Scheme 10. Formal synthesis of Manzacidin A and C 


\subsection{Michael Addition Aromatization Cascade}

$C_{2}$-symmetric bis-triflamides were also employed as synthetic tools in the construction of biologically actives molecules. Seminal studies by Jørgensen outlined the ability of bis-sulfonamide $\mathbf{5 7}$ to promote enantioselective additions of indoles to nitro-olefins (Scheme 11). ${ }^{[32]}$ Thereafter, the same catalyst was successfully used, in combination with $10 \mathrm{~mol} \%$ of $\mathrm{AcOH}$, to perform elaborate double Michael addition-aromatization cascades. ${ }^{[33]}$ This reaction leads to the formation of tetrahydrocarbazoles $\mathbf{5 8}$ with cis,trans stereotriads. Among the products prepared this way, 58a was obtained in $81 \%$ yield, 86:14 dr and 84\% ee. After recrystallization, the same compound was isolated in 47\%, >99:1 dr and >99\% ee and was converted in frovatriptan 59 and ramatroban analogs 60 in two and three steps respectively.

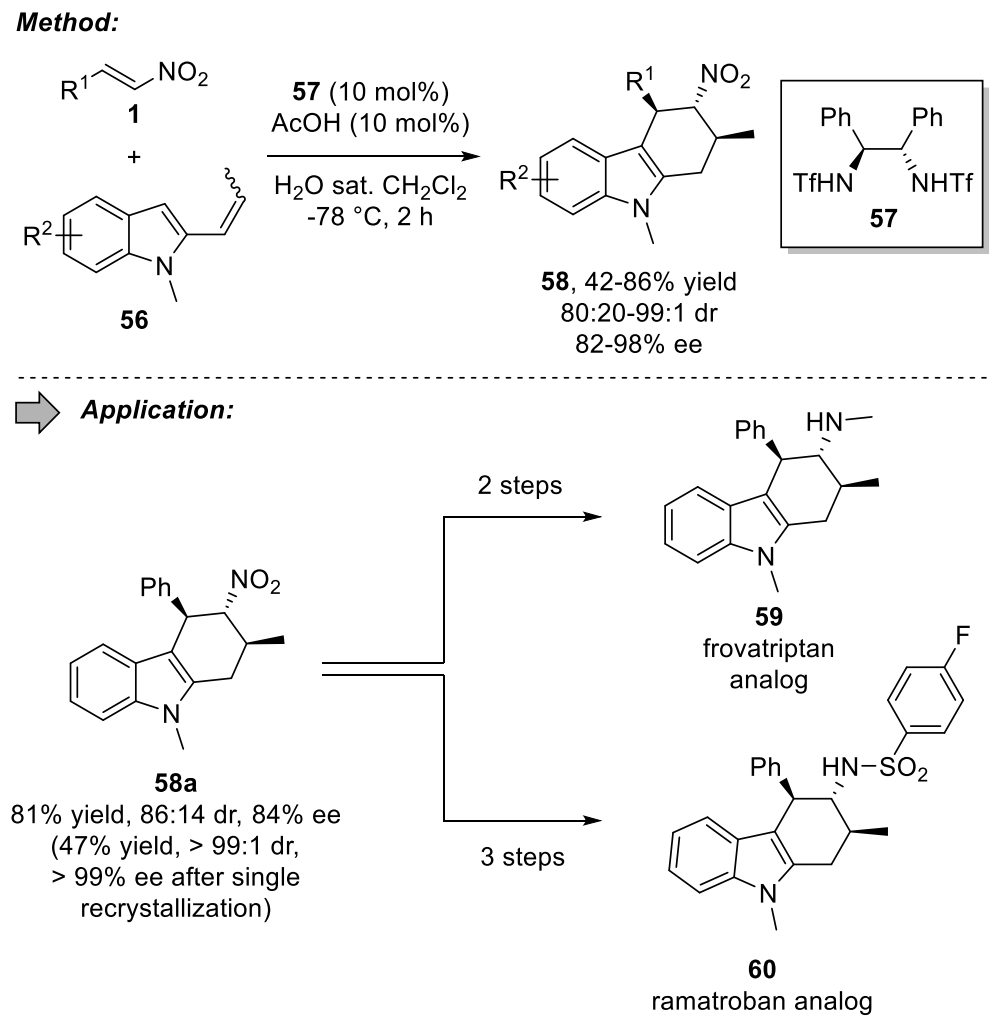

Scheme 11. Synthesis of frovatriptan and ramatroban analogues

\section{2- C-C Bond Formation By Enantioselective Nucleophilic Additions Onto Activated Imines ${ }^{[34]}$}

Imines efficiently participate in enantioselective nucleophilic additions to afford nitrogensubstituted stereocenters. Due to their propensity to convert imines into highly electrophilic iminium ions, chiral Brønsted acids represent excellent catalysts for the development of 
enantioselective reactions. A broad range of nucleophiles can be used in these transformations resulting in the asymmetric formation of new C-C bonds. Hence, Brønsted acid-catalyzed enantioselective additions on imines were extensively considered to choose suitable disconnections when doing the retrosynthetic analysis of $\alpha$-stereogenic amines.

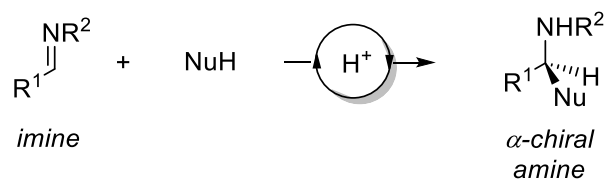

Scheme 12. General scheme of the Brønsted acid-catalyzed nucleophilic addition onto imines

\subsection{Hantzsch Ester Hydride (HEH) Transfer ${ }^{[35,36]}$}

Direct asymmetric reduction of $\mathrm{N}$-alkyl imines by transfer hydrogenation mediated by a Brønsted acid and HEH as hydrogen source has been disclosed by the List group. ${ }^{[37]}$ The $\mathrm{N}$-alkyl amines products are important building blocks in the construction of the core of for a plethora of pharmaceuticals and agrochemicals. The challenge associated with the $\mathrm{N}$-alkyl imine substrates consist in the high basicity of the amines products which can inhibit the catalyst with a consequent luck of turnover of the catalytic cycle. Thus the stronger disulfonimide (DSI) $\mathbf{6 3}$ has been chosen as catalyst and the reduction proceeds in the presence of $\mathrm{Boc}_{2} \mathrm{O}$, in order to get in situ protection of the amines. The methodology has been successfully applied to the synthesis of three pharmaceuticals. (S)-Rivastigmine 64a is used for the treatment of Alzheimer's disease; the asymmetric reduction of imine 61 a led the $N$-Boc protected amine 65 in $92 \%$ yield and $88 \%$ ee. Reduction with $\mathrm{LiAlH}_{4}$ delivered the $\mathrm{N}, \mathrm{N}$-dimethyl amine which was subjected to deprotection of the methoxy group on the aromatic ring to give the corresponding phenol in $76 \%$ yield and $>99 \%$ ee after single recrystallization. Formation of the carbamate with $\mathrm{N}$-ethyl- $\mathrm{N}$-methylcarbamoyl chloride in the presence of $\mathrm{NaH}$ allowed to recover the desired pharmaceutical in only four steps, $64 \%$ overall yield and $>99 \%$ ee. NPS $R$-568 hydrochloride 69 is a calcimimetic compound used for the treatment of hyperparathyroidism, while $(R)$-fendiline $\mathbf{7 0}$ is used for the treatment of coronary heart disease. Both are synthesized following a one pot procedure consisting in the in situ formation of the imine from the commercially available ketones, followed by enantioselective transfer hydrogenation and Boc protection. NPS R-568 hydrochloride 69 and $(R)$-fendiline $\mathbf{7 0}$ were achieved after single crystallization in $\mathrm{HCl}$ /dioxane ( $82 \%$ overall yield, $>99 \%$ ee) or TFA (78\% overall yield, $95 \%$ ee) respectively. 

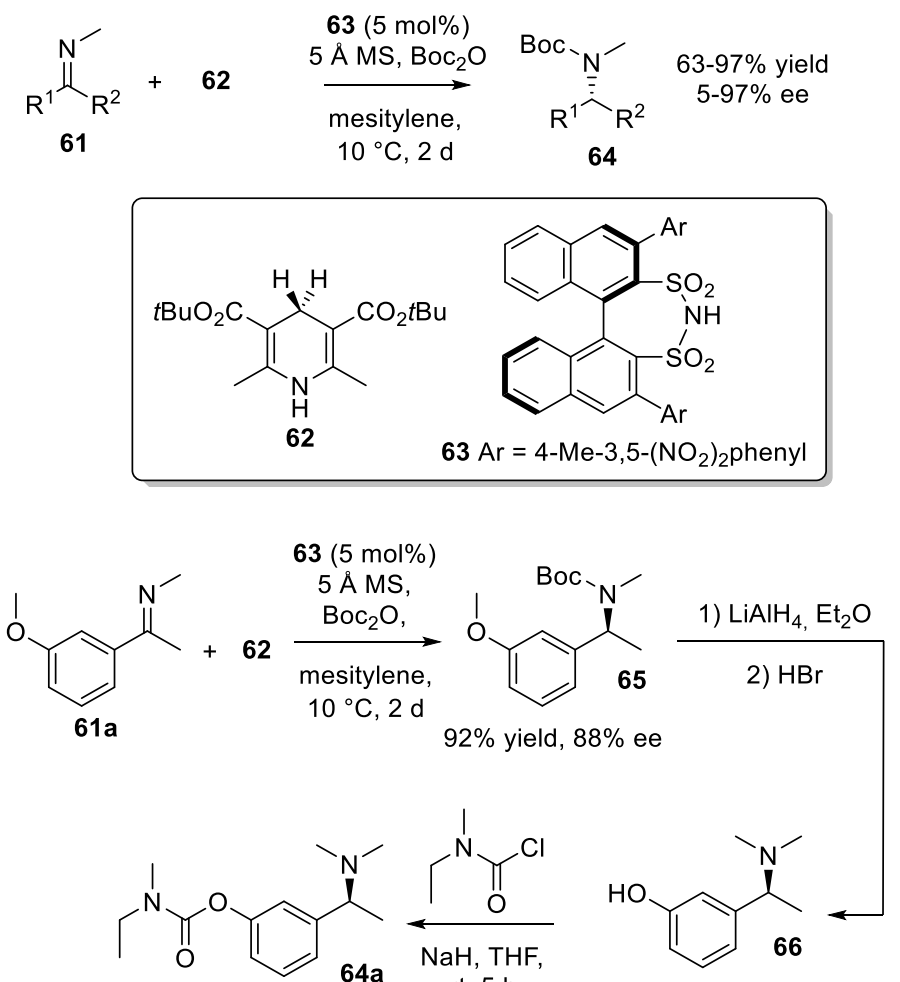

(S)-Rivastigmine 4 steps $\mathrm{rt}, 5 \mathrm{~h}$

$88 \%$ yield over 2 steps

$76 \%$ yield, $>99 \%$ ee

$64 \%$ overall yield

after single recrystallization $>99 \%$ ee<smiles>COc1cccc(C(C)=O)c1</smiles>

1) 5 Å MS, mesitylene, 2) $63(5 \mathrm{~mol} \%), \mathrm{Boc}_{2} \mathrm{O}$,<smiles>NCCCc1ccccc1Cl</smiles>

3) $\mathrm{HCl}$ (dioxane), $50{ }^{\circ} \mathrm{C}, 4 \mathrm{~h}$

$68 a$

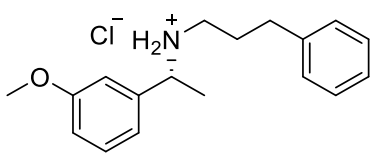

NPS R-568 Hydrochloride 69 $82 \%$ overall yield, $>99 \%$ ee after single recrystallization
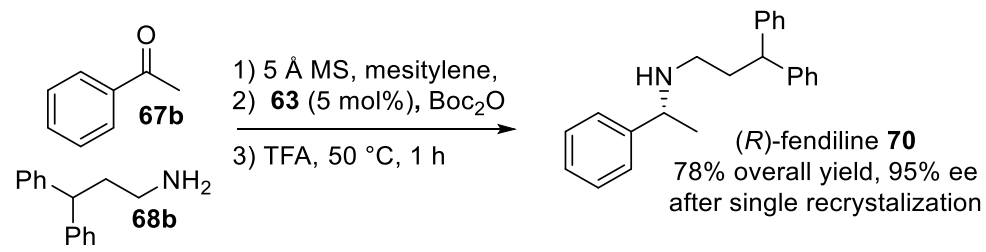

Scheme 13. Synthesis of (S)-rivastigmine, NPS $R-568 . \mathrm{HCl}$ and $(R)$-fendiline

\subsection{Strecker Reaction ${ }^{[38]}$}

The Strecker reaction has attracted considerable attention among synthetic chemists because of the utility of the resulting $\alpha$-aminonitriles in the synthesis of natural products and biological molecules. Therefore, development of asymmetric, catalytic versions of this Strecker 
reaction have been the subject of numerous researches. The thiourea catalyst $\mathbf{7 2}$ developed by Jacobson is a notable example. Inspired by his work, Itoh co-workers described enantioselective Strecker reaction for the synthesis of tetrahydroisoquinoline alkaloids. The reaction of cyclic imine 71 in the presence of HCN using Jacobsen's thiourea catalyst $\mathbf{7 2}$ afforded desired product $\mathbf{7 3}$ in $86 \%$ yield and with $95 \%$ ee. Hydrolysis of the cyano group followed by standard transformations led to (-)-calycotomine 74.
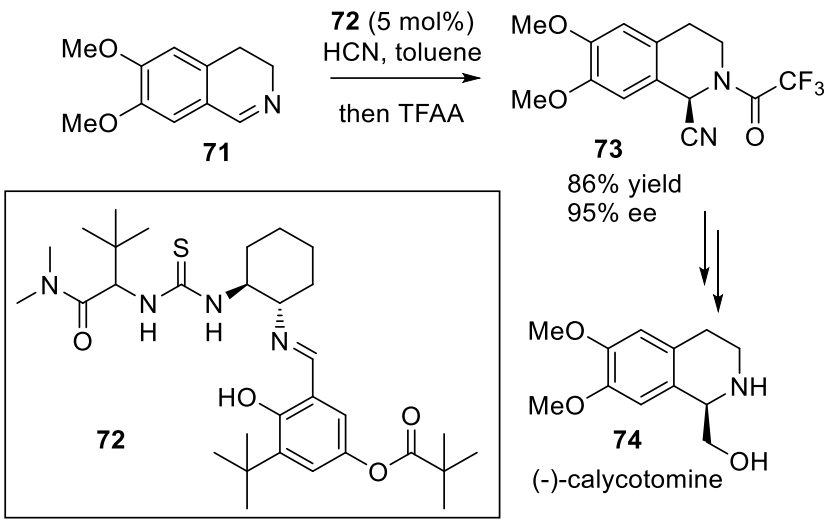

Scheme 14. Synthesis of (-)-calycotomine

Fluorine containing group are very attractive in medicinal chemistry, biology and drug discovery due to its unique properties. In the course of the development of new method to prepare enantiopure $\alpha$-amino acids, Zhou and co-workers developed, ${ }^{[39]}$ in 2011 , an enantioselective Strecker reaction catalyzed by bifunctionnal thiourea 41 (Scheme 15). Starting to fluorinated protected imine, this methodology delivered fluorinated cyano amine with excellent yield and ee. $\alpha$-amino acids 77 can be obtained after 2 steps in 66\% overall yield from the cyano precursor 76 . This work not only provided a nice entry to such compounds but also revealed an intriguing reactivity. It has been also noted that 1 equivalent of HFIP was a good additive to the reaction media, increasing the kinetic of the reaction. An excess of that additive decreased the yield, probably by interfering in the hydrogen bonding network of the catalyst and the imine.

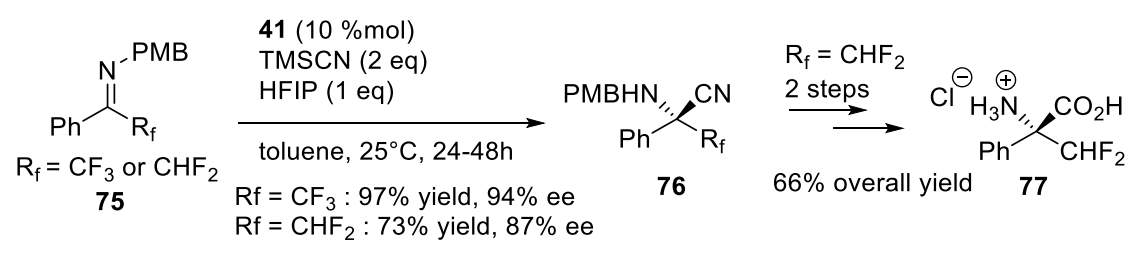

Scheme 15. Synthesis of fluorinated $\alpha$-amino acids by enantioselective Streker reaction 


\subsection{Allylation Of Imines ${ }^{[40]}$}

Brønsted acid catalyzed allylations of imines result in the stereocontrolled formation of one $\mathrm{C}-\mathrm{C}$ bond and are particularly interesting for the preparation of non-cyclic chiral amines. A striking example is that of the original BINOL-catalyzed enantioselective allylation of acyl imines set up by Schaus. ${ }^{[41]}$ The method was based on the formation of a chiral allylation agent by combining allyldiisopropoxyboronate and an appropriate BINOL-derived catalyst 78 (Scheme 16). Resulting diolboronate complex $\mathbf{7 9}$ is a bifunctional species bearing a Lewis acidic boron center and a Brønsted acidic alcohol, both of them activating acylimine partner $\mathbf{8 0}$. This double interaction provides a highly organized transition state $\mathbf{8 1}$ and ensures that the transformation occurs stereoselectively. Homoallylic amines $\mathbf{8 2}$ were isolated in poor to excellent yields as well as with variable enantiomeric excesses (Scheme 17). The products form valuable building blocks for the syntheses of numerous natural products. Enantioselective allylation of a well-designed acylimine delivered amine $\mathbf{8 0}$ a in $75 \%$ yield and $91 \%$ ee. From this product, antiviral maraviroc $\mathbf{8 3}$ was isolated after only two additional transformations. This enantioselective, protecting group-free synthesis is one-step shorter than the previously reported strategies that introduced chirality by engaging the chiral pool. ${ }^{[42]}$

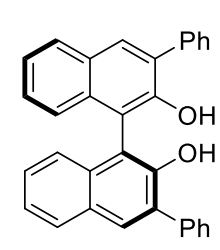

78
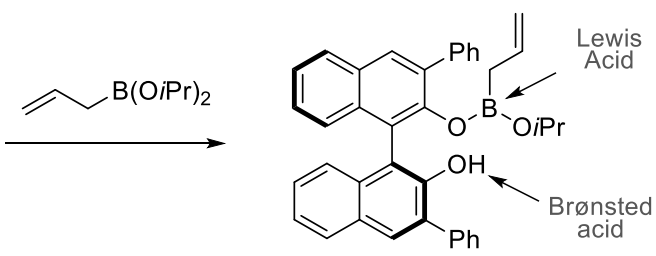

79

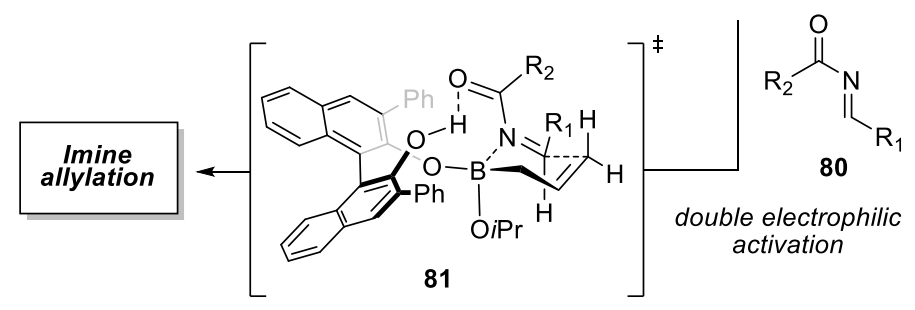

Scheme 16. Proposed transition state for the enantioselective imines allylation catalyzed by BINOL-derived catalysts. 
Method:
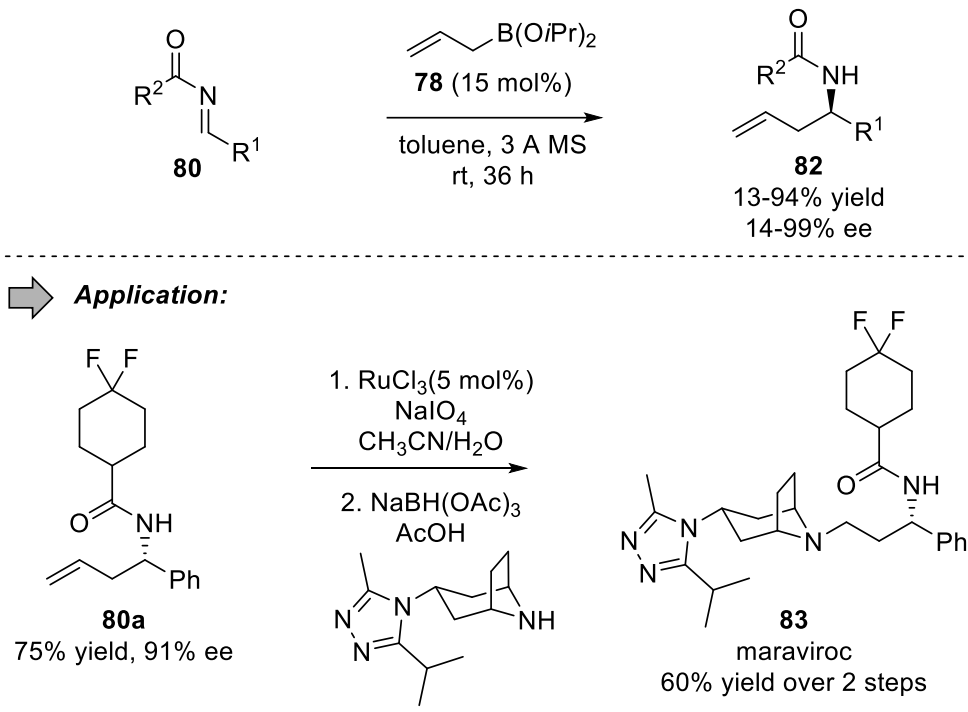

Scheme 17. Synthesis of maraviroc

In 2013, Hoveyda and coworkers also brought a significant contribution to the field of organocatalyzed allylation of imines and carbonyls derivatives. [43] They reported the use of Brønsted acid catalyst $\mathbf{8 4}$ derived from valine able to form an active allylation agent by chelation with pinacolallylborane (Scheme 18). Compared to Schaus' system, boronate complex intermediate 85 displays an additional intramolecular hydrogen bond. The resulting formal positive charge increases Lewis acidity on the boron atom and facilitates coordination of the $\mathrm{N}$-phosphinoylimines substrates $\mathbf{8 6}$. These closer interactions between the different partners in transition state 87 result in improved selectivities and shorter reaction times. Indeed, $N$-protected homoallylic amines 88 were delivered in $4-6 \mathrm{~h}$ in good yields and with enantiopurities up to $99 \%$ ee (Scheme 19). Moreover, the method positively relies on stable organoboron reagents and easily accessible catalysts. The reaction appeared highly versatile and was directly transposed to enantioselective allylation of isatins 89. Again, the degree of enantiocontrol was excellent and enabled the authors to reach, in few steps, several advanced intermediates in the synthesis of natural products. Optically pure carbinol 90a was isolated in 94\% yield and is a precursor in the synthesis of madindoline A 91 described by Hayashi. ${ }^{[44]}$ For its part, 90b was already reported as a valuable intermediate to access some representative members 92 of the convolutamydines family. ${ }^{[45]}$ 

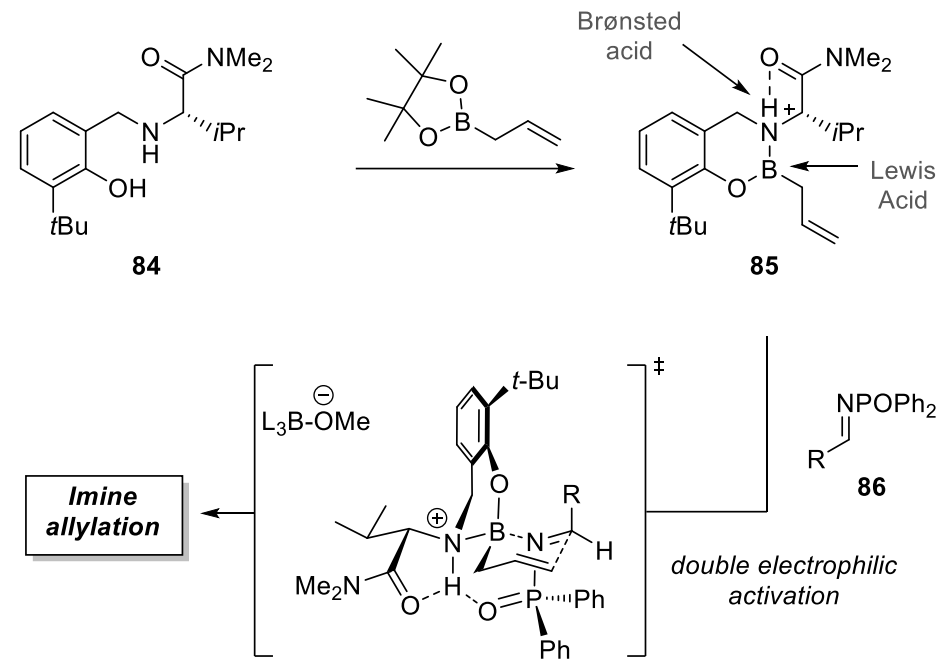

87

Scheme 18. Proposed transition state for the enantioselective imines allylation catalyzed by a valine-derived catalysts.

Method:
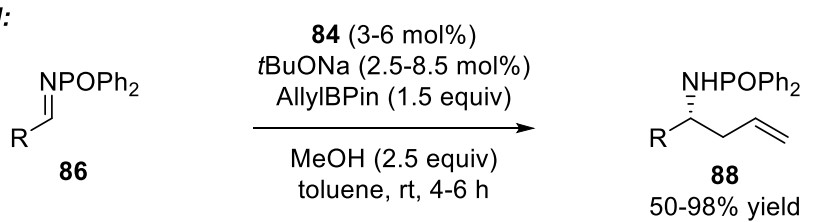

88
$50-98 \%$ yi

$50-98 \%$ yield

76 to $>99 \%$ ee
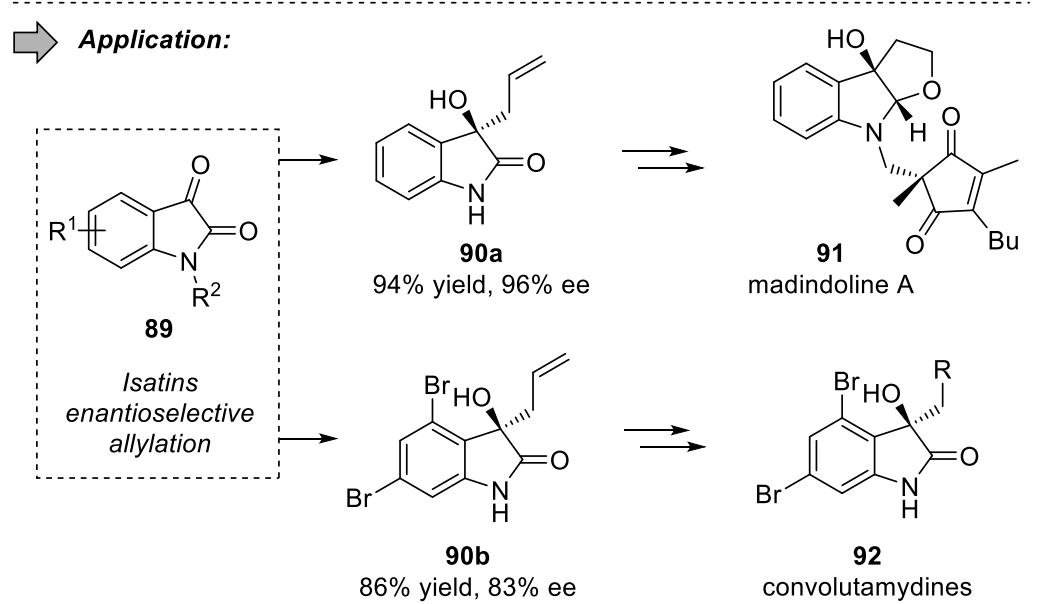

$94 \%$ yield, $96 \%$ ee

Scheme 19. Synthesis of madindoline A and convolutamydines

\subsection{Aza-Sakurai Cyclization}

The aza-Sakurai cyclization, which involves the reaction of an iminium ion with an allylsilane, is powerful transformations in the synthesis of indolizidines. In 2016, Jacobsen and coworkers ${ }^{[46]}$ described a thiourea acid-catalyzed aza Sakurai-Hosomi reaction between aminal and allylsilane 
93. They proposed a transition state model 95 to account for the observed enantioelectivity in which the thiourea catalyst 94 acts as an anion receptor to generate chiral ion pair between $\mathrm{N}$ acyliminium and chloride-thiourea as well as an internal Lewis base to activate the allylsilane. Optically enriched indolizidines 96 was isolated in $85 \%$ yield and is a precursor in the synthesis of (-)-tashiromine 97. After oxidative cleavage of the terminal olefin followed by reduction with $\mathrm{LiAlH}_{4}$ led to natural product in excellent yield.

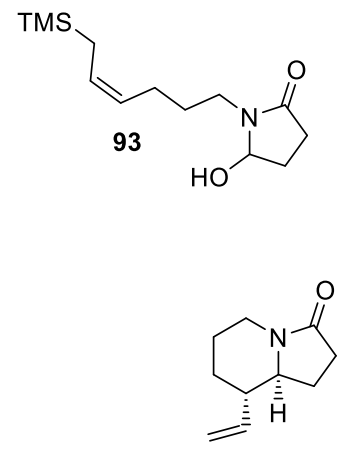

(-)-tashiromine 97

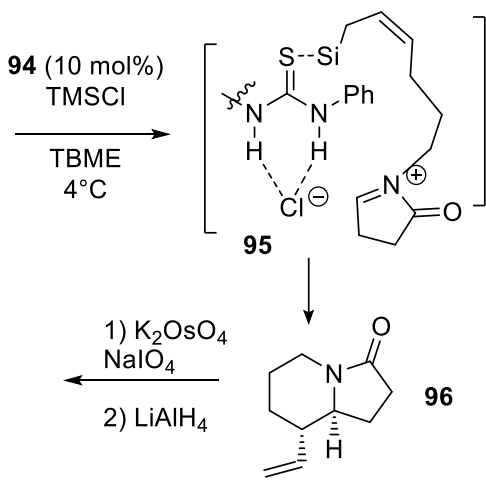

$85 \%$ yield, $92 \%$ ee

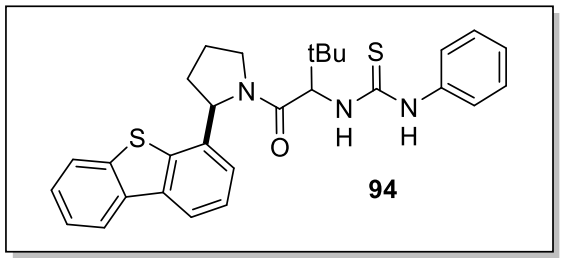

Scheme 20. Synthesis of (-)-tashiromine

\subsection{Pictet-Spengler Reaction ${ }^{[47]}$}

The Pictet-Spengler cyclization is one of the most potent transformations in the synthesis of alkaloids derivatives, like tetrahydroisoquinolines or tetrahydro-b-carbolines. The reaction proceeds by the formation of an iminium intermediate followed by an intramolecular Friedel-Crafts addition. The overall reaction then results in the creation of two new $\mathrm{C}-\mathrm{N}$ and $\mathrm{C}-\mathrm{C}$ bonds. In recent years, the development of enantioselective versions of the Pictet-Spengler reaction was intensively investigated and several Brønsted acid-catalyzed methods were efficiently introduced. In 2004, Jacobsen reported the first asymmetric thiourea catalyzed

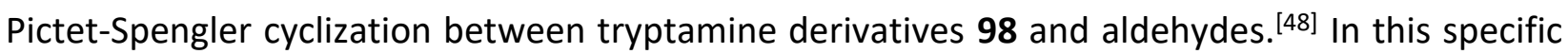
case, the imine intermediate was activated as a $\mathrm{N}$-acyliminium ion 101 in the presence of acetyl chloride and thiourea catalyst 99 (Scheme 21). The chiral environment required to perform the enantioselective Friedel-Crafts cyclization was provided by the formation of a chiral chloride 
counteranion. The reaction proceeds with high degrees of enantioselectivity and was rightly used to synthesize (-)-yohimbine 102. ${ }^{[49]}$ To this end, tryptamine was reacted with 3-((tBudiphenylsilyl)oxy)propanal in the presence of acylating agent and catalyst 99. This single acylation/Pictet-Spengler condensation sequence afforded the ABC-core of the target molecule by forming tetrahydro- 6 -carboline 100 a in $81 \%$ yield and with $94 \%$ ee. Only nine additional steps were then necessary to complete the synthesis of final product 102.

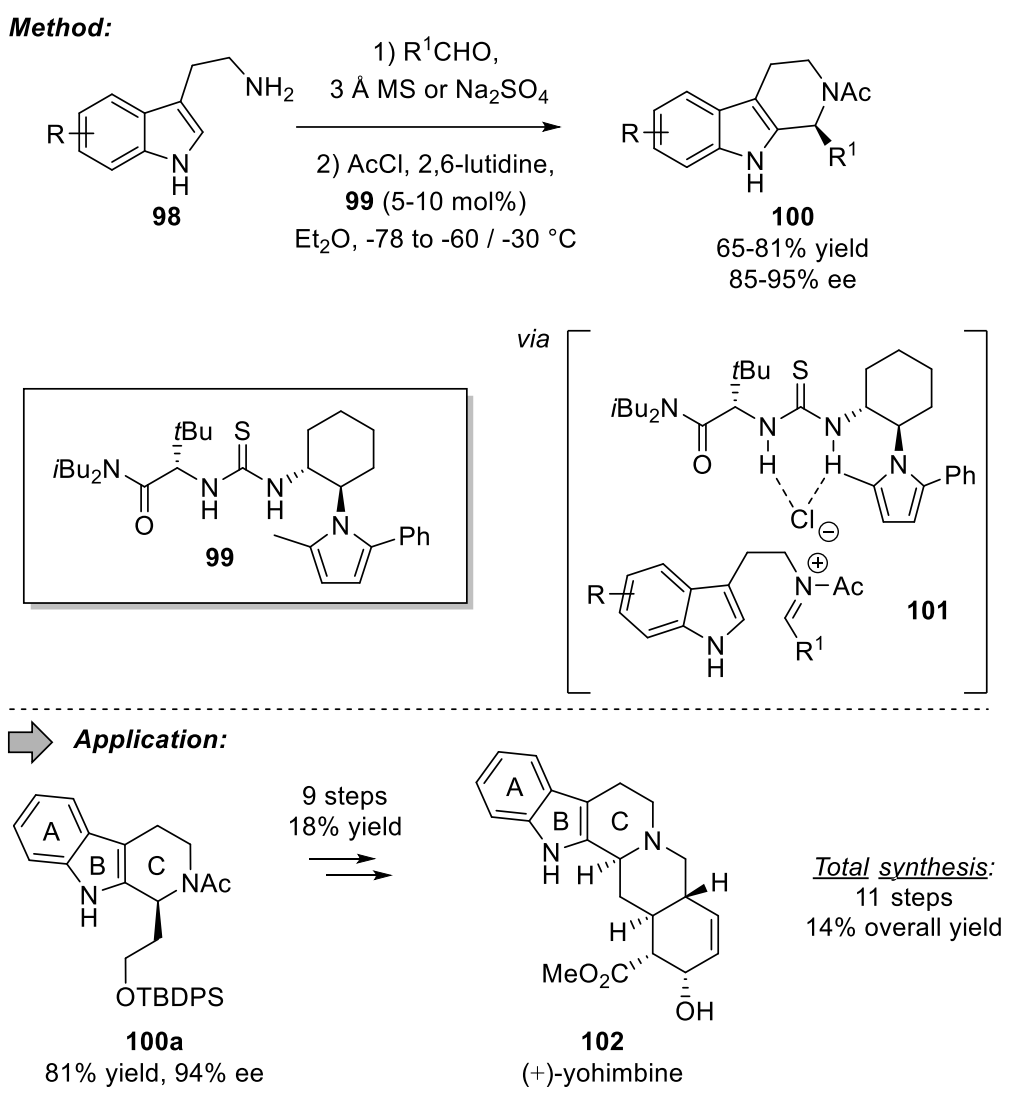

Scheme 21. Synthesis of (+)-yohimbine

Based on the same strategy, the enantioselective Pictet-Spengler cyclization was involved in the asymmetric synthesis of indolizidones and quinolizidones 105 (Scheme 22). ${ }^{[50]}$ In this case, the $\mathrm{N}$-acyliminium intermediate was generated by dehydration of hydroxylactams 103 in the presence of TBSCl. Chiral ion pair 106 resulting from the association of the chloride anion and thiourea 104 underwent smooth cyclization at low temperature. Building on this method, Jacobsen designed a 4-steps synthesis of (+)-harmicine 108 involving intermediate 107a. 
Method:
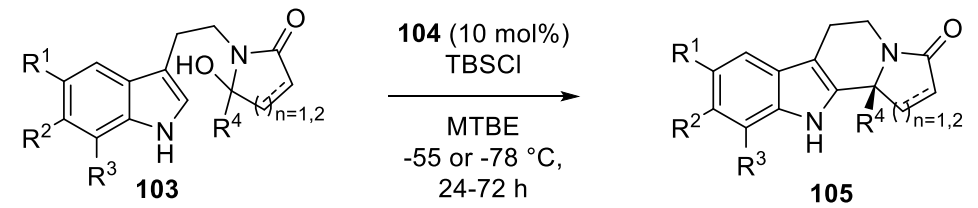

$52-94 \%$ yield, $81-99 \%$ ee

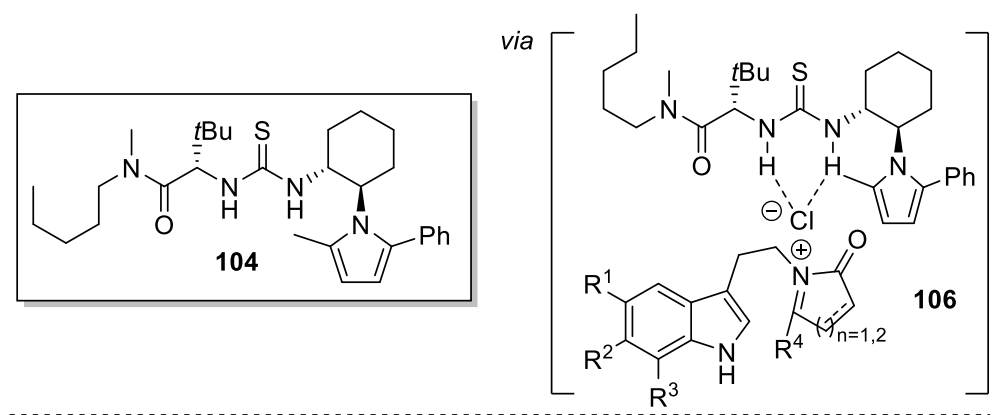

$\Rightarrow$ Application:

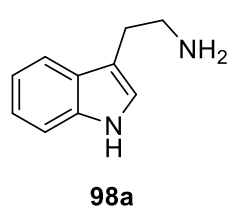

1. succinic anhydride, toluene/AcOH (1/3) $120^{\circ} \mathrm{C}, 24 \mathrm{~h}$

2. $\mathrm{NaBH}_{4}, \mathrm{MeOH}$, $0^{\circ} \mathrm{C}$

3. $104(10 \mathrm{~mol} \%)$ TBSCI, MTBE

$-55^{\circ} \mathrm{C}, 48 \mathrm{~h}$

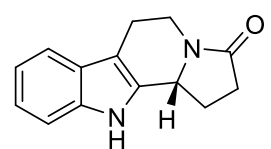

$107 a$

$65 \%$ over 3 steps $97 \%$ ee

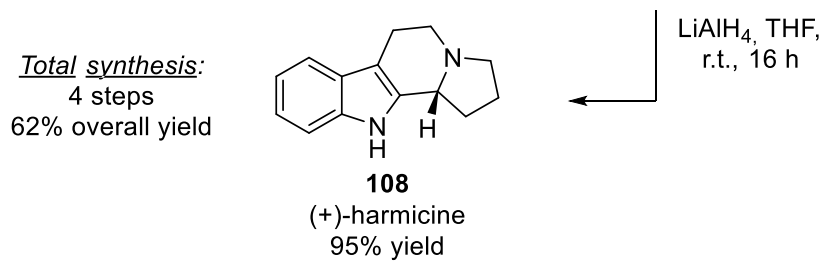

Scheme 22. Synthesis of (+)-harmicine

In 2012, van Maarseveen, Hiemstra, and co-workers ${ }^{[51]}$ developed a chiral thiourea-catalyzed Pictet-Spengler reaction between indole 109 and aldehyde 110. The overall process was efficiently catalyzed by thiourea catalyst $\mathbf{4 1}$ derived from a Cinchona alkaloid (10 mol\%) and delivered the tetrahydro- 6 -carboline derivative $\mathbf{1 1 1}$ in $91 \%$ yield with high enantioselectivity (89\% ee). The synthetic value of this method was further demonstrated with total syntheses of the mitragynine, paynantheine and speciogynine (Scheme 23). 


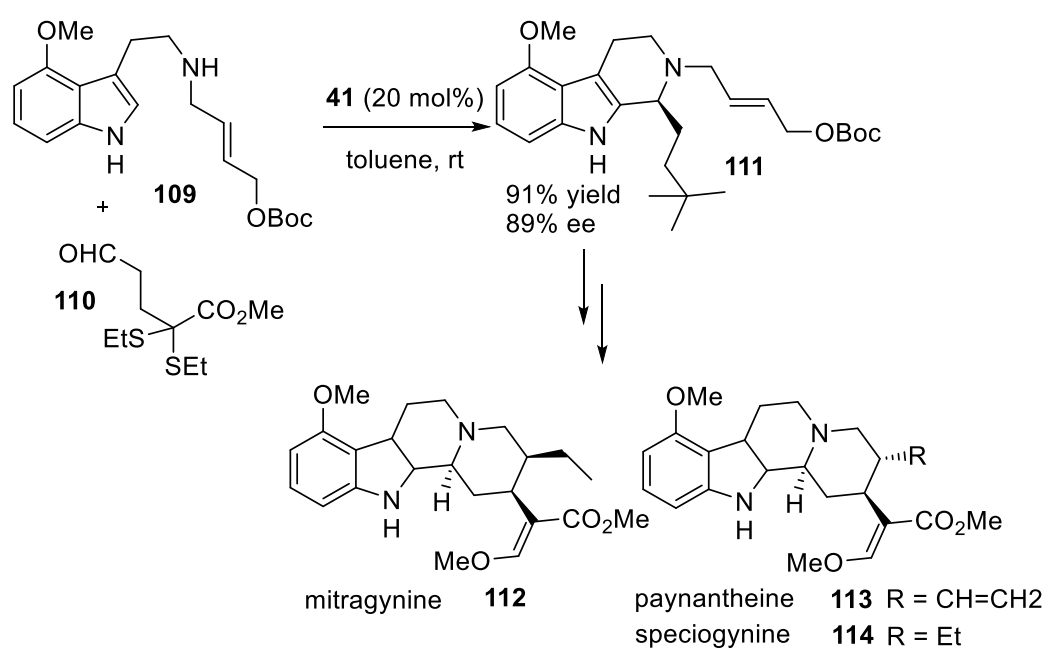

Scheme 23. Synthesis of mitragynine, paynantheine and speciogynine

\section{3- C-C Bond Fformation By Enantioselective Nucleophilic Additions Onto Carbonyle}

Contrary to imines, related few enantioselective additions onto carbonyl groups have been developed. This difference of exemplification can be explained be the difficulty of chiral Brønsted acid catalysts to discriminate the two electronic lone pairs of the oxygen atoms (Scheme 24). However, such transformations remain highly appealing for the asymmetric synthesis of alcohol derivatives and several examples will be reported in this sections.

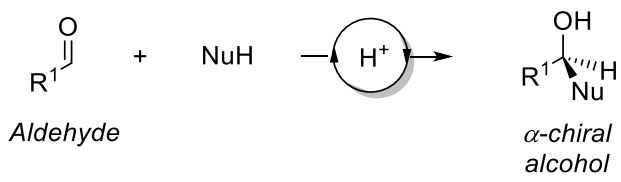

Scheme 24. General scheme of the Brønsted acid-catalyzed nucleophilic addition onto icarbonyles

\subsection{Henry Reaction ${ }^{[52]}$}

The nitroaldol (Henry) reaction is a valuable tool for the synthesis of $\boldsymbol{B}$-nitroalcohols and to functionalized intermediates such as nitroalkenes, 1,2-amino alcohols and $\alpha$-hydroxy carboxylic acids. In 2006, Nagazawa and co-workers used an asymmetric version of the Henry reaction with their guanidinium based bis-thiourea catalyst $117^{[53]}$ (Scheme 25) for the total synthesis of $(4 S$, $5 R$ )-epi-Cytoxazone 120 , a type-2 cytokine selective inhibitor. ${ }^{[54]}$ The Henry reaction proceed via a controlled anti transition state 118, furnishing syn-nitro alcohol 119 with a good $76 \%$ yield and excellent selectivity (95\% ee and 90:10 syn/anti ratio). With the new formed nitro alcohol in hand, installation of the cyclic carbamate in a $43 \%$ yield over 2 steps completed the total synthesis, with a 33\% overall yield from aldehyde 120 . 


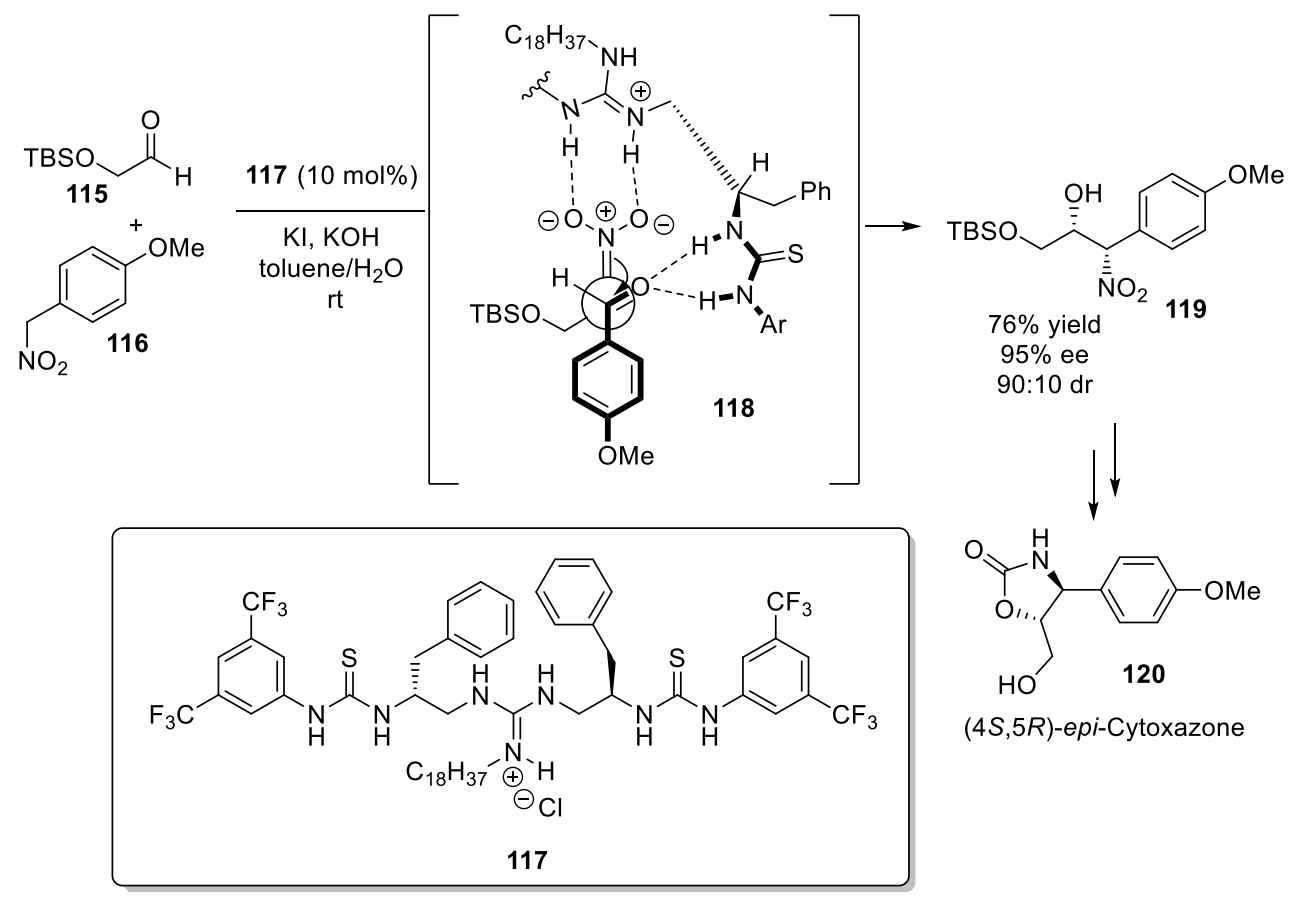

Scheme 25. Enantioselective Henry reaction in the total synthesis of (4S, 5R)-epi-Cytoxazone

In 2011, Wang and coworkers reported the total synthesis of spirobrassinin 125 (Scheme 26). ${ }^{[55]}$ One of the key step was an enantioselective Henry reaction with simple isatin (121) and nitromethane using cupreine as a catalyst affording the desired Henry product in almost quantitative yield with $91 \%$ ee. The enantiopure compound $\mathbf{1 2 4}$ was isolated after recrystallization. Once again, the bifunctional aspect of catalyst was invoked to explain the degree of stereocontrol. As depicted in suggested transition state $\mathbf{1 2 5}$, the ketone undergoes a Brønstedacid activation while the Brønsted basic nitogen atom of the catalyst activates the nitrometane. Then, the nitro group of $\mathbf{1 2 4}$ was reduced by hydrogenation to give primary amine 126 in $92 \%$ yield. From 122, only three additional steps were required to reach spirobrassinin 127. 


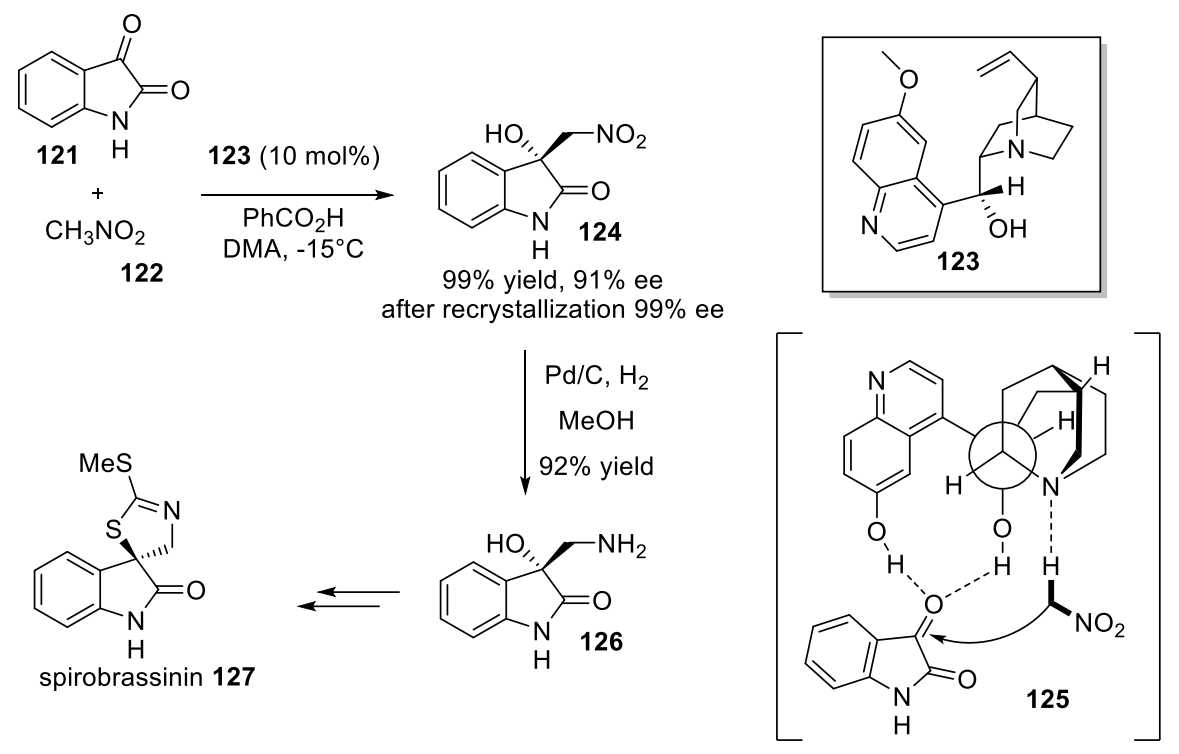

Scheme 26. Enantioselective Henry reaction in the total synthesis of spirobrassinin

\subsection{Cyanosilylation ${ }^{[56]}$}

Asymmetric addition of TMSCN (TMS = trimethylsilyl) to ketones is the most popular strategy to produce optically active cyanohydrins. Deng and co-workers ${ }^{[57]}$ developed enantioselective cyanosilylation of ketone 128 catalyzed by a modified cinchona alkaloid catalyst 129 providing cyanohydrin $(R)-130$ in quantitative yield and $92 \%$ ee. This intermediate was used for the first enantioselective synthesis of bisorbicillinol 132 (Scheme 27).

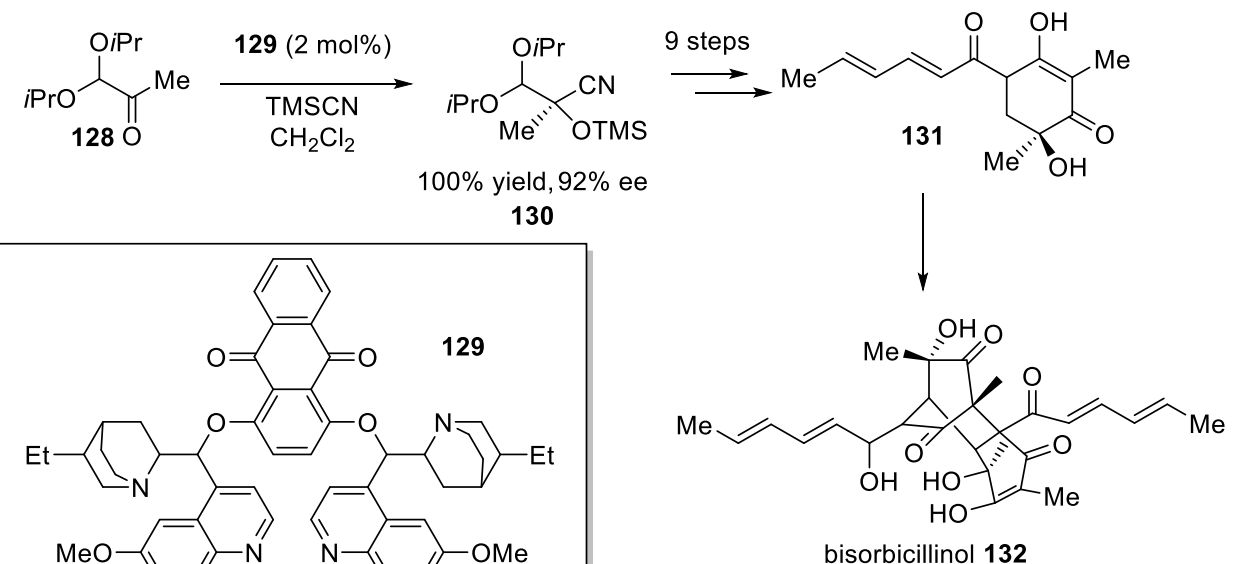

Scheme 27. Enantioselective Synthesis of bisorbicillinol 


\subsection{Morita-Baylis-Hillman Reaction ${ }^{[58]}$}

The Morita-Baylis-Hillman ( $\mathrm{MBH}$ ) reaction has been recognized as one of the most effective method to generate densely functionalized $\alpha$-methylene-b-hydroxycarbonyl derivatives 135 , which can serve as valuable building blocks for the synthesis of biologically relevant compounds as well as complex natural products. Hatekeyama and coworkers ${ }^{[59]}$ have developed the first highly enantioselective MBR reaction between aldehydes and activated acrylates catalyzed by 6 isocupreidine (6-ICD, 134). The reaction of 1,1,1,3,3,3-hexafluoroisopropyl acrylates (HFIPA) 133 with aldehydes in the presence of a catalytic amount of $\mathbf{1 3 4}$ afforded the $R$ allylic alcohols $\mathbf{1 3 5}$ in moderate yields (40-58\%), but with excellent enantioselectivities (up to $99 \%$ ee, Scheme 28). In 2006, the same authors also reported a highly diastereoselective $\mathrm{MBH}$ reaction of chiral $N$-Boc- $\alpha$-aminoaldehydes for the synthesis of $\alpha$-methylene- $\beta$-hydroxy- $\gamma$-amino acid derivatives $135{ }^{\left[{ }^{[60]}\right.}$ Subsequently, this approach was applied for an enantioselective synthesis of potent immunosuppressant (-)-mycestericin E (136) and a formal synthesis of biologically active epopromucin B (138, Scheme 28). ${ }^{[61]}$

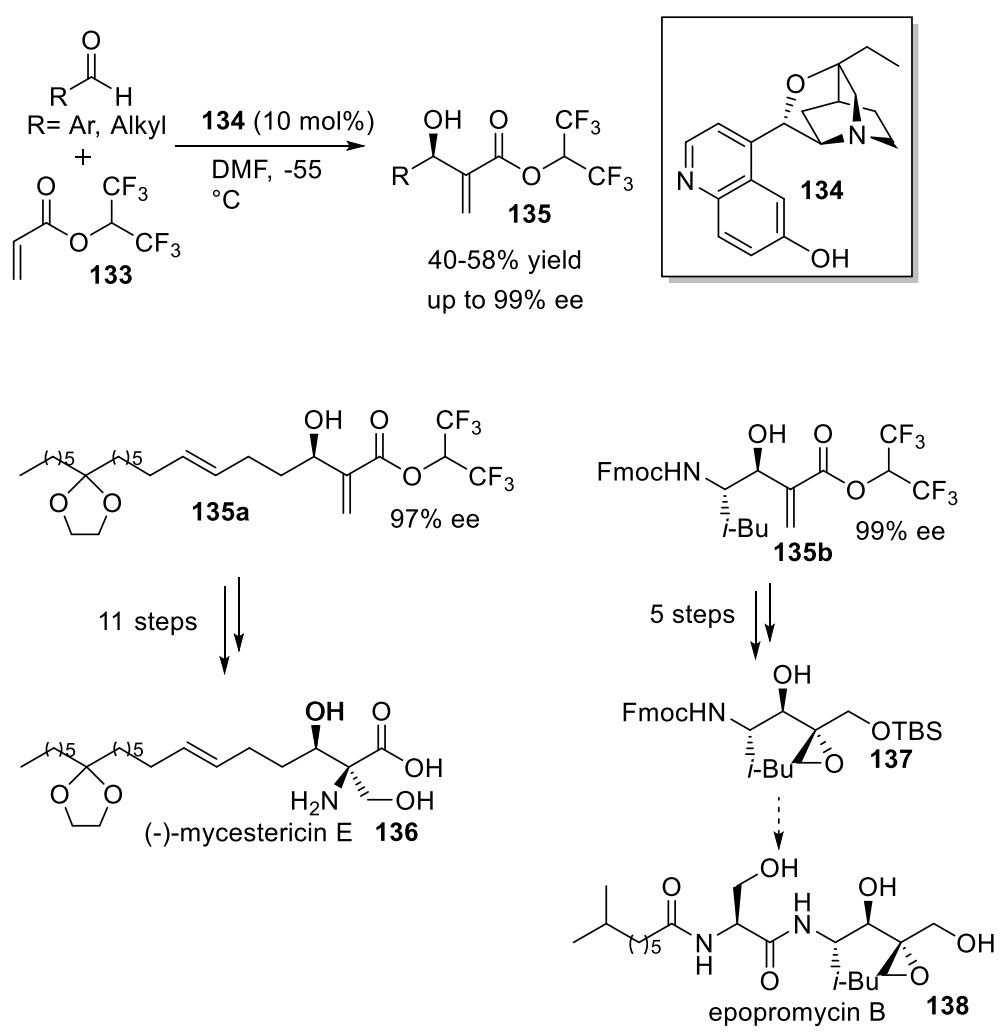

Scheme 28. Synthesis of mycestericin E (32) and a formal synthesis of epopromucin 


\section{4- Diels-Alder Reaction}

The Diels-Alder reaction (DAR), is one of the most powerful reactions to build elaborated 6-membered cycle and has been used in many total synthesis of natural products. ${ }^{[62]}$ Many variant has been developed and various asymmetric versions have been developed.

In the course of controlling stereocenters in the DAR, Ricci reported in 2008 an interesting entry to tricyclic indolines with a full control of the stereocenters. ${ }^{[63]}$ Using catalyst 141, 3-vinylindole 139 and $N$-phenyl maleimide 140 reacted successfully to give the Diels-Alder adduct in an impressive $91 \%$ yield and $98 \%$ ee. In one step, 2 carbon-carbon bonds and 3 stereocenters was created with a total control (Scheme 29). The proposed transition step involves a Brønsted acid activation of the carbonyl of the maleimide (dienophile), lowering it LUMO energy. The nitrogen of the quinuclidine ring act as a Brønsted base, activating the 3-vinylindole (diene), increasing it HOMO energy. With the so formed indoline 143 in hand, several chemical manipulation gives the tetrahydrocarbazole 144 in $23 \%$ overall yield and with conservation of a good ee (93\%). This product is a key intermediate in the synthesis of the natural product Tubifolidine $\mathbf{1 4 5}$ and was used in its total synthesis by Shibasaki et al. ${ }^{[64]}$

In 2013, an efficient entry to carbazolespiroindole was published by Barbas III and co-workers, ${ }^{\text {[65] }}$ starting from $\mathrm{N}$-Boc protected methyleneindolinone 146 and 3-vinylindole 139, catalyzed by bis-thiourea 141. Those substrates possess interesting biological activities and are found in some naturals products, ${ }^{[66]}$ which makes them very attractive for organic chemists. 

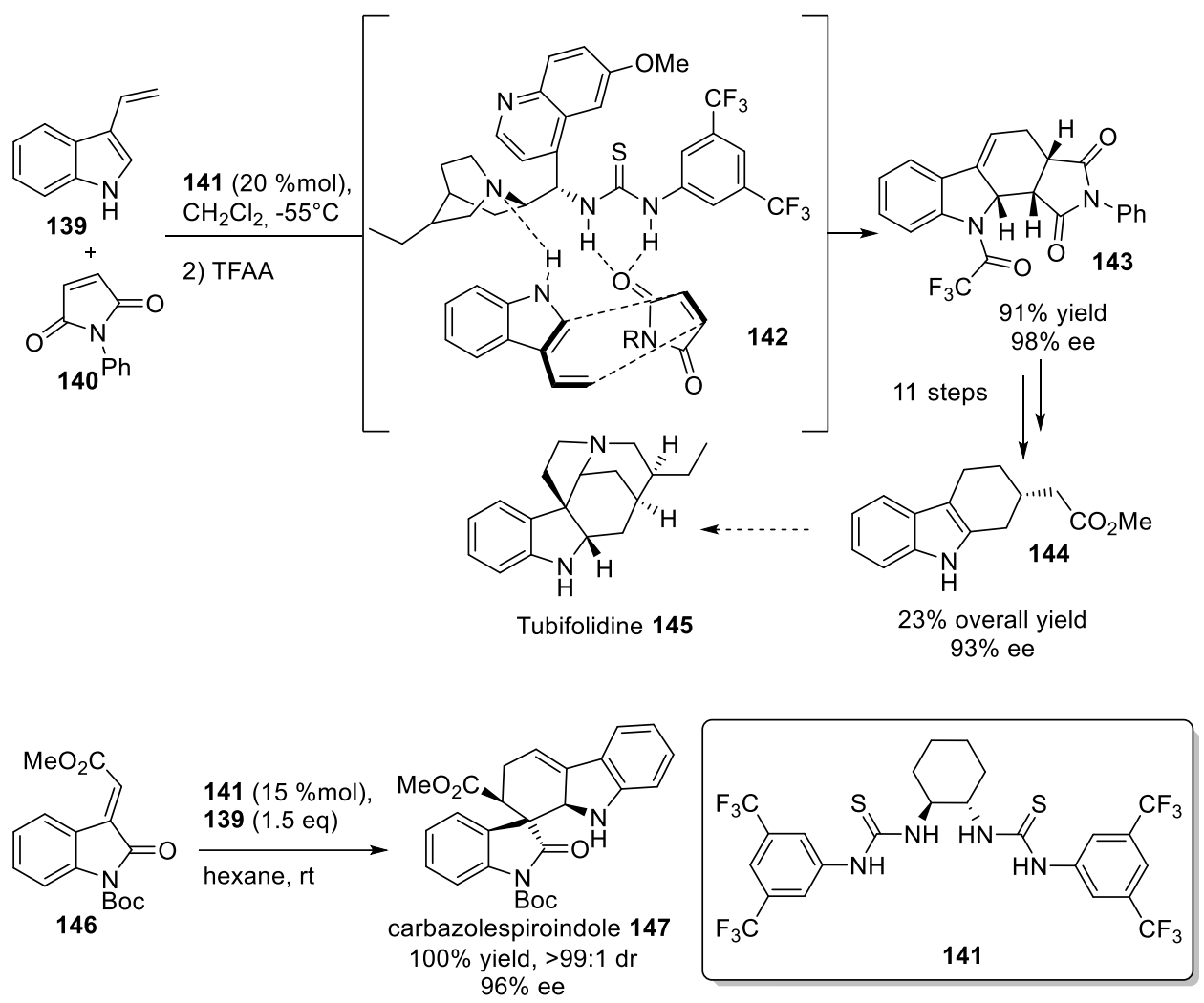

Scheme 29. Stereocontroled synthesis of tubifolidine and carbazolespiroindole

\subsection{Povarov Reaction ${ }^{[67]}$}

The organocatalyzed strategy to build asymmetric $\mathrm{C}-\mathrm{C}$ bonds from imines was also efficiently applied to the Povarov reaction. Formally it constitutes an inverse electron-demand Diels-Alder cycloaddition between an electron-poor azadiene and an electron-rich dienophile. The whole process allows the formation of two new $\mathrm{C}-\mathrm{C}$ bonds and offers a direct and atom-economical route to the versatile tetrahydroquinoline scaffold. With this in mind, Jacobsen and co-workers reported an urea-assisted Povarov reaction between $N$-arylimines 148 and various dienophiles including enamides 150 and enecarbamates 152 (Scheme 30).[68] The optimized reaction conditions were identified as a combination of sulfinamido urea 149 and $o$-nitrobenzenesulfonic acid (NBSA) in a 2:1 ratio. Desired products 151 were formed as a single exo diastereomer in good yields and with excellent ee's. When the dienophilic olefin was contained in a cycle, the transformation resulted in complex fused tricyclic moieties $\mathbf{1 5 3}$ with three contiguous stereogenic 
centers. Interestingly, compound 153a was reached in one step from 148a in 76\% yield and 95\% ee and was described as a key intermediate in Ma's synthesis of martinelline 154. ${ }^{69]}$
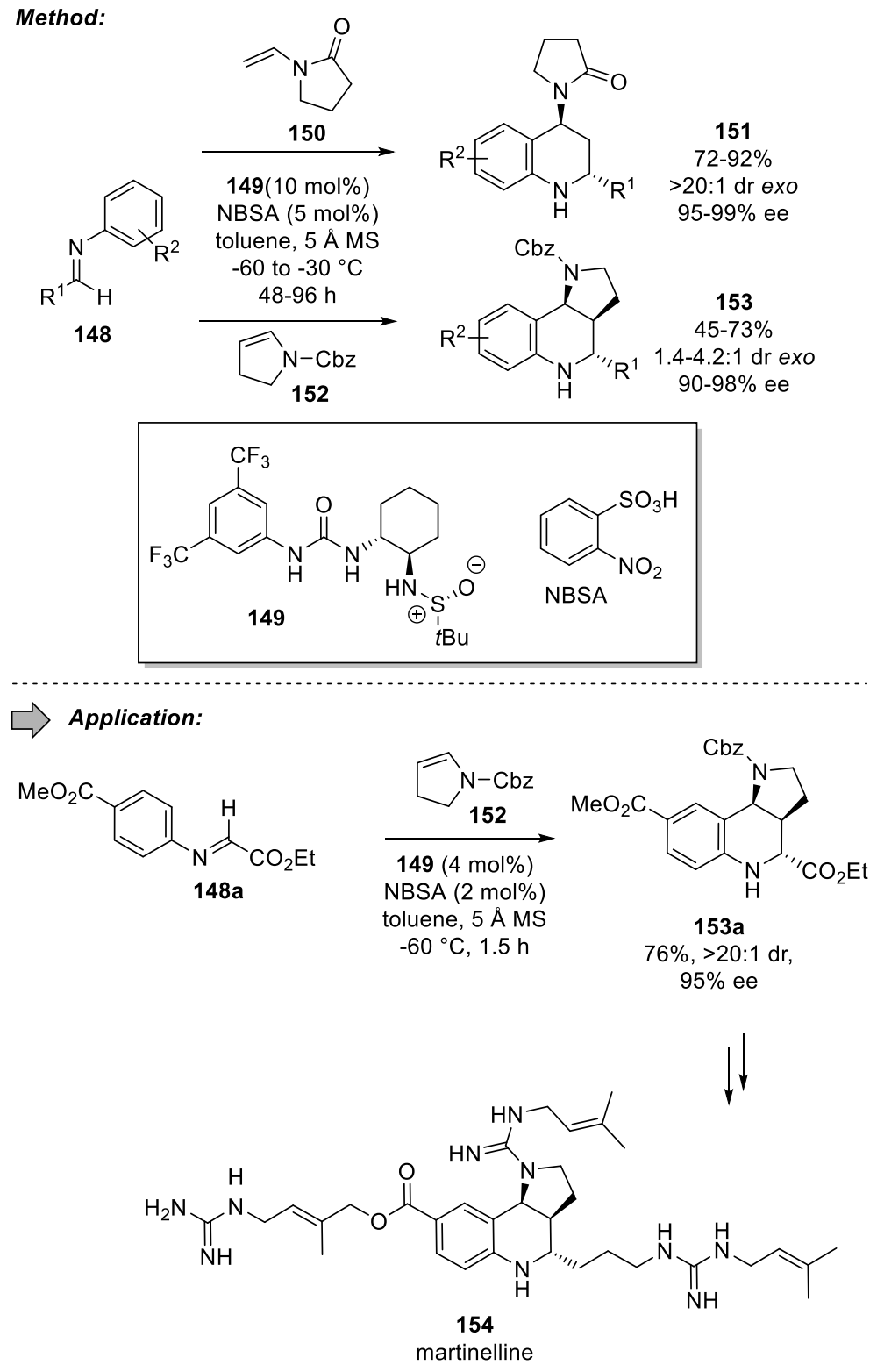

Scheme 30. Synthesis of martinelline derivatives

\section{5- Substitution Reaction}

Nucleophilic substitution of 3-(1-tosylalkyl)indoles $\mathbf{1 5 5 ^ { [ 7 0 ] }}$ is an efficient method to construct alkaloids. In 2005, Gong investigated this elegant strategy for the purposes of synthesizing optically active spirooxindoles. They explored the use of chiral bifunctional thiourea catalysts with 
3-indolyl(aryl)sulfonylmethanes. A combination of thiourea catalyst $41^{[69]}$ and $\mathrm{K}_{2} \mathrm{CO}_{3}$ was observed to be optimal for the addition of oxindoles 156 to the vinylogous imines 157 (Scheme 31). The bifunctional thiourea catalysts acts as Brønsted base, deprotonating the pronucleophile, and a hydrogen bond donor for both the nucleophile and the electrophile, directing the reaction partners to adopt the ternary complex operating in the transition state. The yields and enantioselectivities were generally very good, albeit with moderate diastereoselectivity. Resulting oxindole 157 obtained with $98 \%$ ee and 2.5:1 dr, was then converted into trigolute B 158 in seven steps and a 39\% yield over the whole synthesis.

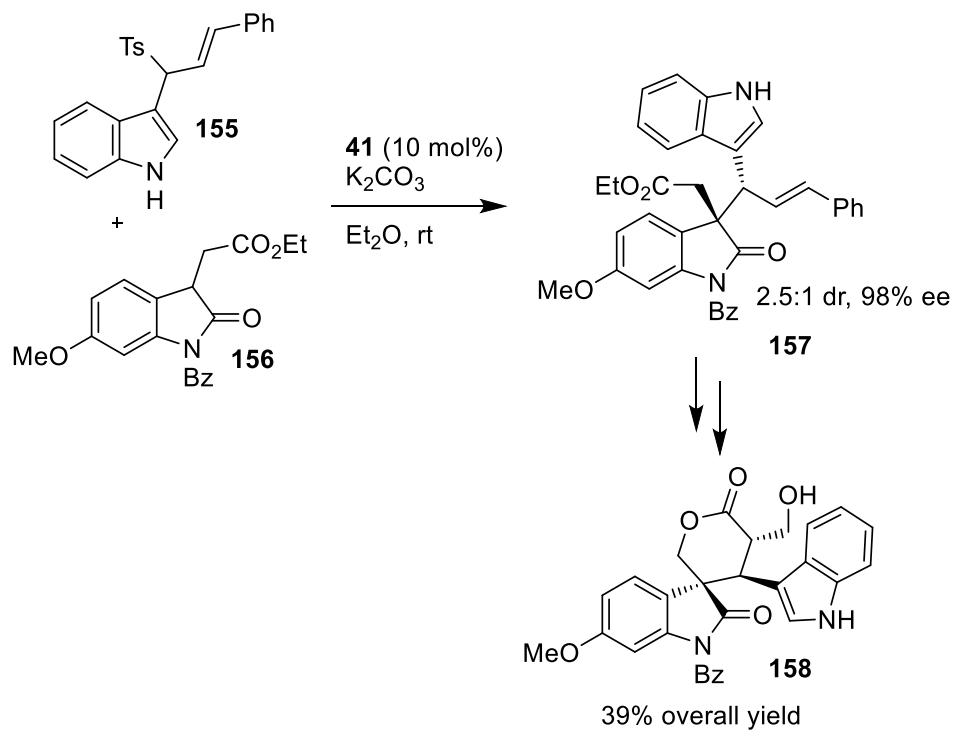

Scheme 31. Synthesis of trigolute

Gong group continued their studies towards cyclotryptamine alkaloids. ${ }^{[71]}$ They carried out the addition of nitroalkanes to 3-tosyl-3-indolyloxindoles by the same bifunctional catalyst $\mathbf{4 1}$ described above. The addition on nitromethane 160 proceeded in 76-98\% yield of 161 and gave enantiomeric excess of 89-99\% (Scheme 32). However, poor diastereoselectivity was observed when nitroethane was used (1.2:1). Using the newly developed methodologies, the Gong group was able to synthesize a key intermediate for the synthesis of (+)-gliocladin C 162 in a catalytic enantioselective fashion. 

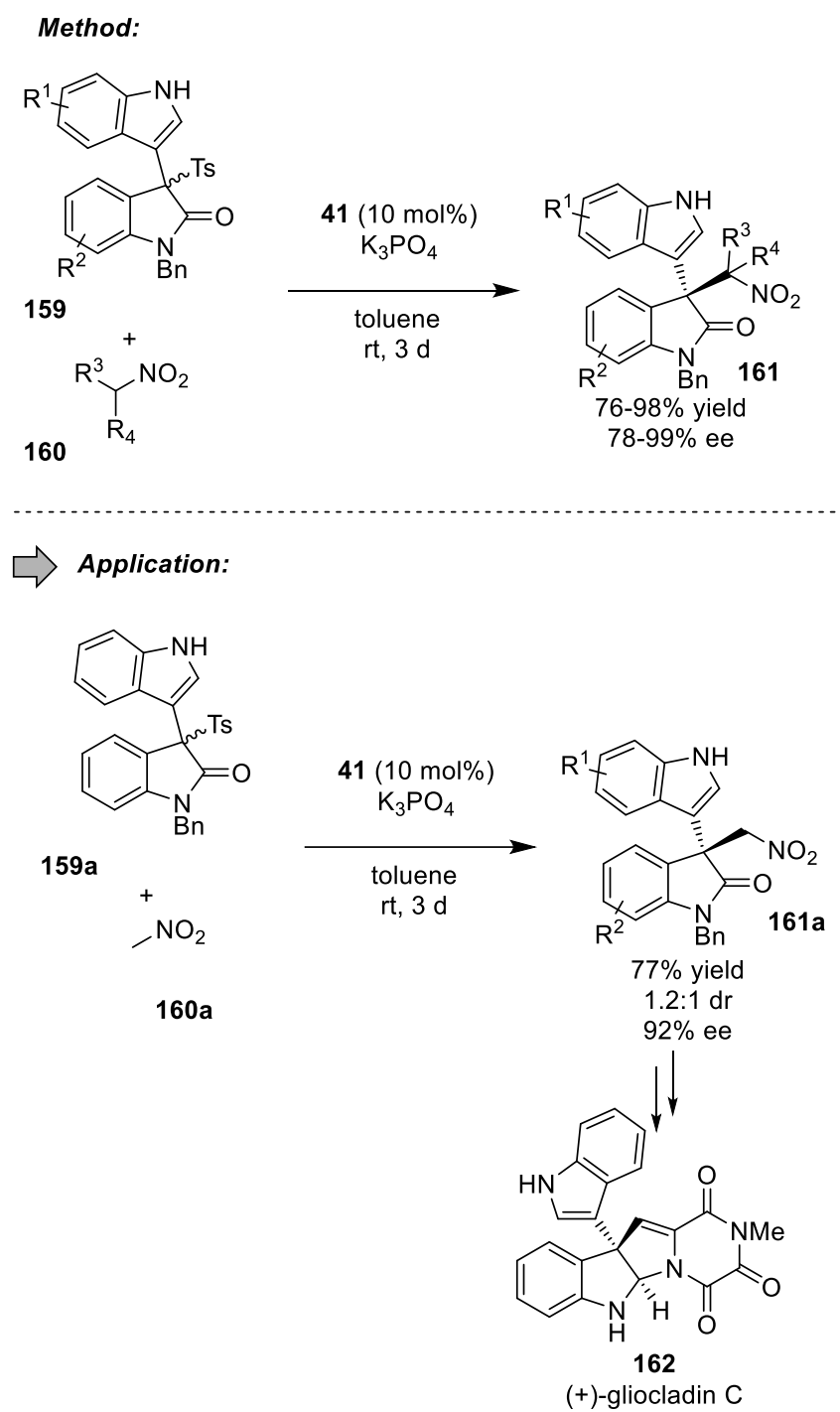

Scheme 32. Synthesis of gliocladin C

\section{Conclusion}

Implementation of chiral organocatalysis in the area of pharmaceutical chemistry to simultaneously introduce one or several of the stereogenic centers present on the target structure has the potential to improve overall selectivity, shorten synthetic routes and increase their convergence. Chiral organocatalysts are often easy to handle compared to other conditions, involving Lewis acids for example, while permitting the use of more readily available starting materials. Examples of use of organocatalytic methods for the construction of diverse natural or synthetic active molecules are already numerous and keep on accumulating. Thereby demonstrating the adequation of these tools to solve problems met when trying to access such 
chiral, complex and polyfunctional structures. Now that efficiency of chiral organocatalysis at the laboratory scale seems to be established. The next challenge in our opinion is to find ways to increase the adoption rate of this class of processes in development and production contexts. Generalization of this powerful tool would potentially have a great benefit in terms of ease of operation as well as sustainability.

[1] R. Crossley, Chirality and the Biological Activity of Drugs, CRC Press, 1995.

[2] H. Caner, E. Groner, L. Levy, I. Agranat. Drug Discov. Today, 2004, 9, 105.

[3] M. J. Gaunt, C. C. C. Johansson, A. McNally, N. T. Vo, Drug Discov. Today, 2007, 12, 8.

[4] For reviews about asymmetric organocatalysis in total synthesis, see: a) E. Marqués-López, R. P. Herrera, M. Christmann, Nat. Prod. Rep. 2010, 27, 1138; b) C. Grondal, M. Jeanty, D. Enders, Nat. Chem. 2010, 2, 167; c) B.F. Sun, Tetrahedron Lett. 2015, 56, 2133; c) M. Abbasov, D. Romoa; Nat. Prod. Rep. 2014,31, 1318.

For a book on this topic: M. Waser, Asymmetric Organocatalysis in Natural Product Syntheses, Spinger-Verlag Wien, 2012.

[5] For a review about organocatalytic asymmetric synthesis of chiral nitrogenous heterocycles and natural products, see: J. Yu, Y. Zhou, D.-F. Cheng, L.-Z. Gong, Pure Appl. Chem. 2014, 86, 1217.

[6] a) P. R. Schreiner, Chem. Soc. Rev. 2003, 32, 289; b) P. M. Pihko, Angew. Chem. Int. Ed. 2004, 43, 2062; c) A. G. Doyle, E. N. Jacobsen, Chem. Rev. 2007, 107, 5713; d) R. J. Phipps, G. L. Hamilton, F. D. Toste, Nat. Chem. 2012, 4, 603; e) K. Brak, E. N. Jacobsen, Angew. Chem. Int. Ed. 2013, 52, 534; f) M. Mahlau, B. List, Angew. Chem. Int. Ed. 2013, 52, 518; g) D. Parmar, E. Sugiono, S. Raja, M. Rueping, Chem. Rev. 2014, 114, 9047; h) T. Akiyama, K. Mori, Chem. Rev. 2015, 115, 9277; i) X. Fang, C.-J. Wang, Chem. Commun. 2015, 51, 1185.

[7] D. Enders, C. Grondal, M. R. M. Hüttl, Angew. Chem. Int. Ed. 2007, 46, 1570.

[8] For a book on this topic, see: P.-F. Xu, W. Wang, Catalytic cascade Reaction, Wiley-VCH, Weinhein, 2014.

[9] J. Merad, C. Lalli, G. Bernadat, J. Maury, G. Masson, Chem. Eur. J. 2018, 24, 3925.

[10] For general reviews about asymmetric Michael additions, see: a) Y. Zhang, W. Wang, Catal. Sci. Technol. 2012, 2, 42; b) H. Pellissier, Adv. Synth. Catal. 2012, 54, 237; c) M. H. Majid, H. Parvin, H. Hoda, Curr. Org. Chem. 2014, $18,489$.

[11] For reviews about asymmetric conjugate additions to nitro-olefins, see: a) O. M. Berner, L. Tedeschi, D. Enders, Eur. J. Org. Chem. 2002, 1877; b) D. Almasi, A. Alonso, C. Najera, Tetrahedron: Asymmetry, 2007, 18, 299; c) S. Sulzer-Mosse, A. Alexakis, Chem. Commun. 2007, 43, 3123; d) D. Roca-López, D. Sadaba, I. Delso, R.P. Herrera, T. Tejero, P. Merino, Tetrahedron: Asymmetry, 2010, 21, 2561; e) R. Somanathan, D. Chavez, F. A. Servin, J. A. Romero, A. Navarrete, M. Parra-Hake, G. Aguirre, D. P. C. Anaya, J. González, Curr. Org. Chem. 2012, 16, 2440; f) D. A. Alonso, A. Baeza, R. Chinchilla, C. Gómez, G. Guillena, I. M. Pastor, D. J. Ramón, Molecules, $2017,22,895$.

[12] a) M. S. Taylor, E. N. Jacobsen, Angew. Chem. Int. Ed. 2006, 45, 1520; b) A. G. Doyle, E. N. Jacobsen, Chem. Rev. 2007, 107, 5713; c) Z. Zhang, P. R. Schreiner, Chem. Soc. Rev. 2009, 38, 1187.

[13] T. Bui, S. Syed, C. F. Barbas III, J. Am. Chem. Soc. 2009, 131, 8758.

[14] T. Matsuura, L. E. Overman, D. J. Poon, J. Am. Chem. Soc. 1998, 120, 6500.

[15] Q.-S. Yu, A. Brossi, Heterocycles, 1988, 27, 745.

[16] K. Asakawa, N. Noguchi, S. Takashima, M. Nakada, Tetrahedron: Asymmetry, 2008, 19, 2304.

[17] H. F. Russell, E. J. Waller, N. R. Ducharmell, J. Org. Chem. 1991, 56, 871.

[18] B. M. Trost, Y. Zhang, J. Am. Chem. Soc. 2006, 128, 4590.

[19] M. Kato, K. Yasui, M. Yamanaka, K. Nagasawa, Asian J. Org. Chem. 2016, 5, 380. 
[20] For a review about asymmetric conjugate additions to acrylates, see: E. Reyes, U. Uria, J. L. Vicario, L. Carrillo, (2016). The Catalytic, Enantioselective Michael Reaction. In Organic Reactions.

[21] P. Chen, X. Bao, L.-F. Zhang, M. Ding, X.-J. Han, J. Li, G.-B. Zhang, Y.-Q. Tu, C.-A. Fan, Angew. Chem. Int. Ed. 2011, $50,8161$.

[22] T. Okino, Y. Hoashi, Y. Takemoto, J. Am. Chem. Soc. 2003, 125, 12672.

[23] F. Marini, S. Sternativo, F. Del Verme, L. Testaferri, M. Tieccoa, Adv. Synth. Catal. 2009, 351, 103.

[24] T. Zhang, L. Cheng, S. Hameed, L. Liu, D. Wang; Y.-J. Chen, Chem. Commun. 2011, 47, 6644.

[25] T. Buyck, Q. Wang, J. Zhu, Angew. Chem. Int. Ed. 2013, 52, 12714.

[26] For reviews about double Michael sequences, see: a) M. Ihara, K. Fukumoto, Angew. Chem. Int. Ed. 1993, 32, 1010; b) S. Nayak, P. Panda, S. Bhakta, S. K. Mishra, S. Mohapatra, RSC Adv. 2016, 6, 96154.

[27] Y. Hoashi, T. Yabuta, Y. Takemoto, Tetrahedron Lett. 2004, 45, 9185.

[28] Y. Wang, Y.-C. Luo, H.-B. Zhang, P.-F. Xu, Org. Biomol. Chem. 2012, 10, 8211.

[29] D. R. Li, A. Murugan, J. R. Falck, J. Am. Chem. Soc. 2008, 130, 46.

[30] T. Okino, Y. Hoashi, Y. Takemoto, J. Am. Chem. Soc. 2003, 125, 12672.

[31] a) Y. Wang, X. Liu, L. Deng, J. Am. Chem. Soc. 2006, 128, 3928; b) B. Wang, F. Wu, Y. Wang, X. Liu, L. Deng, J. Am. Chem. Soc. 2007, 129, 768.

[32] W. Zhuang, R. G. Hazell, K. A. Jørgensen, Org. Biomol. Chem. 2005, 3, 2566.

[33] X.-F. Wang, J.-R. Chen, Y.-J. Cao, H.-G. Cheng, W.-J. Xiao, Org. Lett. 2010, 12, 1140.

[34] For reviews about asymmetric additions onto imines, see: a) A. G. Doyle, E. N. Jacobsen, Chem. Rev. 2007, 107, 5713; b) M. Petrini, E. Torregiani, Synthesis, 2007, 159; c) B. Yin, Y. Zhang, L.-W. Xu, Synthesis, 2010, 3583; d) J. Vesely, R. Rios Chem. Soc. Rev. 2014, 43, 611; e) A. O. Kataja, G. Masson, Tetrahedron, 2014, 70, 8783. f) For a book about the synthesis of chiral amines, see: T. S. Nugent, Chiral Amine Synthesis: Methods, Developments and Applications Wiley-VCH, Weinhein, 2014.

[35] For reviews on organocatalytic reductions: a) M. Rueping, J. Dufour, F. R. Schoepke, Green Chem. 2011, 13, 1084; b) M. Rueping, E. Sugiono, F. R. Schoepke, Synlett, 2010, 852.

[36] For a review on tetrahydroquinolines see: V. Sridharan, P. A. Suryavanshi, J. C. Menéndez Chem. Rev. 2011, 111, 7157.

[37] V. Wakchaure, P. S. J. Kaib, M. Leutzsch, B. List, Angew. Chem. Int. Ed. 2015, 54, 11852.

[38] For reviews on catalytic asymmetric Strecker reaction of ketimines, see: a) S. J. Connon, Angew. Chem. Int. Ed. 2008, 47, 1176; b) C. Spino, Angew. Chem. Int. Ed. 2004, 43, 1764. For selected examples, see: c) S. Masumoto, H. Usuda, M. Suzuki, M. Kanai, M. Shibasaki, J. Am. Chem. Soc. 2003, 125, 5634; d) J. Wang, X. Hu, J. Jiang, S. Gou, X. Huang, X. Liu, X. Feng, Angew. Chem. Int. Ed. 2007, 46, 8468; e) J. P. Abell, H. J. Yamamoto, J. Am. Chem. Soc. 2009, 131, 15118.

[39] Y.-L. Liu, T.-D. Shi, F. Zhou, X.-L. Zhao, X. Wang, J. Zhou, Org. Lett. 2011, 13, 3826.

[40] For a review on catalytic asymmetric allylation of carbonyls and imines, see: a) M. Yus, J. C. González-Gómez, F. Foubelo, Chem. Rev. 2011, 111, 7774; b) H.-X. Huo, J. R. Duvall, M.-Y. Huang, R. Hong, Org. Chem. Front. 2014, $1,303$.

[41] S. Lou, P. N. Moquist, S. E. Schaus, J. Am. Chem. Soc. 2007, 129, 15398.

[42] D. A. Price, S. Gayton, M. D. Selby, J. Ahman, S. Haycock-Lewandowski, B. L. Stammen, A. Warren, Tetrahedron Lett. 2005, 46, 5005.

[43] D. L. Silverio, S. Torker, T. Pilyugina, E. M. Vieira, M. L. Snapper, F. Haeffner, A. H. Hoveyda, Nature, 2013, 494, 216.

[44] T. Itoh, H. Ishikawa, Y. Hayashi, Org. Lett. 2009, 11, 3854.

[45] G. Cravotto, G. B. Giovenzana, G. Palmisano, A. Penoni, T. Pilati, M. Sisti, F. Stazi, Tetrahedron: Asymmetry, 2006, 17, 3070.

[46] Y. Park, C. S. Schindler, E. N. Jacobsen, J. Am. Chem. Soc. 2016, 138, 14848. 
[47] For a review on the use of the Pictet-Spengler condensation in the synthesis of natural products: J. Stöckigt, A. P. Antonchick, F. Wu and H. Waldmann, Angew. Chem. Int. Ed. 2011, 50, 8538.

M. S. Taylor, E. N. Jacobsen, J. Am. Chem. Soc., 2004, 126, 10558.

D. J. Mergott, S. J. Zuend, E. N. Jacobsen, Org. Lett. 2008, 10, 745.

I. T. Raheem, P. S. Thiara, E. A. Peterson, E. N. Jacobsen, J. Am. Chem. Soc. 2007, 129, 13404.

I. P. Kerschgens, E. Claveau, M. J. Wanner, S. Ingemann, J. H. van Maarseveen, H. Hiemstra, Chem. Commun. 2012, 48, 12243.

F. A. Luzzio, Tetrahedron, 2001, 57, 915.

a) Y. Sohtome, Y. Hashimoto, K. Nagasawa, adv. Synth. Catal. 2005, 347, 1643; b) Y. Sohtomea, N. Takemurab, T. Iguchib, Y. Hashimotoa, K. Nagasawa, Synlett, 2006, 1, 144.

Y. Sohtome, Y. Hashimoto, K. Nagasawa, Eur. J. Org. Chem. 2006, 2894.

L. Liu, S. Zhang, F. Xue, G. Lou, H. Zhang, S. Ma, W. Duan, W. Wang, Chem. Eur. J. 2011, 17, 7791.

For reviews on the preparation and application of cyanohydrins, see: a) R. J. H. Gregory, Chem. Rev. 1999, 99, 3649; b) F. Effenberger, Angew. Chem. Int. Ed. Engl. 1994, 33, 1555. c) M. North, Synlett, 1993, 807. d) H. Deng, M. P. Isler, M. L. Snapper, A. H. Hoveyda, Angew. Chem, Int. Ed. 2002, 41, 1009.

R. Hong, Y. Chen, L. Deng, Angew. Chem. Int. Ed. 2005, 44, 3478.

a) G. Masson, C. Housseman, J. Zhu, Angew. Chem., Int. Ed. 2007, 46, 4514; b) V. Declerck, J. Martinez, F. Lamaty, Chem. Rev. 2009, 109, 1; c) D. Basavaiah, K. V. Rao, R. J. Reddy, Chem. Soc. Rev. 2007, 10, 1581; d) D. Basavaiah, A. J. Rao, T. Satyanarayana, Chem. Rev. 2003, 103, 811; e) E. Ciganek, Org. React. 1997, 51, 201.

Y. Iwabuchi, M. Nakatani, N. Yokoyama, S. Hatakeyama, J. Am. Chem. Soc. 1999, 121, 10219.

A. Nakano, K.Takahashi, J. Ishihara, S. Hatakeyama, Org. Lett. 2006, 8, 5357.

Y. Iwabuchi, M. Furukawa, T. Esumi, S. Hatakeyama, Chem. Commun. 2001, 0, 2030.

K. C. Nicolaou, S. A. Snyder, T. Montagnon, G. Vassilikogiannakis, Angew. Chem. Int. Ed. 2002, 41, 1668.

C. Gioia, A. Hauville, L. Bernardi, F. Fini, A. Ricci, Angew. Chem. Int. Ed. 2008, 47, 9236.

S. Shimizu, K. Ohori, T. Arai, H. Sasai, M. Shibasaki, J. Org. Chem. 1998, 63, 7547.

B. Tan, G. Hernández-Torres, C. F. Barbas III, J. Am. Chem. Soc. 2011, 133, 12354.

a) H. Lin, S. J. Danishefsky, Angew. Chem. Int. Ed. 2003, 42, 36; b) C. V. Galliford, K. A. Scheidt, Angew. Chem. Int. Ed. 2007, 46, 8748; c) T. J. Greshock, A. W. Grubbs, P. Jiao, D. T. Wicklow, J. B. Gloer, R. M. Williams, Angew. Chem. Int. Ed. 2008, 47, 3573; d) K. A. Miller, S. Tsukamoto, R. M. Williams, Nat. Chem, 2009, 1, 63.

For reviews about Povarov reaction, see: a) V. A. Glushkov, A. G. Tolstikov, Russ. Chem. Rev. 2008, 77, 137; b) V. V. Kouznetsov, Tetrahedron 2009, 65, 2721; c) D. Bello, R. Ramón, R. Lavilla, Curr. Org. Chem. 2010, 14, 332; d) V. Sridharan, P. A. Suryavanshi, J. C. Menendez, Chem. Rev. 2011, 111, 7157; e) X. X. Jiang, R. Wang, Chem. Rev. 2013, 113, 5515; d) G. Masson, C. Lalli, M. Benohoud, G. Dagousset, Chem. Soc. Rev. 2013, 42, 902; e) X. X. Jiang, R. Wang, Chem. Rev. 2013, 113, 5515; f) M. Fochi, L. Caruana, L. Bernardi, Synthesis 2014, 46, 135; g) V. Eschenbrenner-Lux, K. Kumar, H. Waldmann, Angew. Chem. Int. Ed. 2014, 53, 11146.

H. Xu, S. J. Zuend, M. G. Woll, Y. Tao, E. N. Jacobsen, Science, 2010, 327, 986.

C. Xia, L. Heng, D. Ma, Tetrahedron Lett. 2002, 43, 9405.

J.-Z. Huang, C.-L. Zhang, Y.-F. Zhu, L.-L Li, D.-F. Chen, Z.-Y. Han, L.-Z. Gong, Chem. Eur. J. 2015, 21, 8389.

J.-Z. Huang, X. Wu, L. Gong, Adv. Synth. Cat. 2013, 355, 2531. 